\title{
Fault Current Mitigation and Voltage Support Provision by Microgrids with Synchronous Generators
}

Liu, Xubin; Li, Canbing; Shahidehpour, Mohammad; Chen, Xinyu; Yi, Jun; Wu, Qiuwei; Sun, Kai; Zhou, Bin

Published in:

IEEE Transactions on Smart Grid

Link to article, DOI:

10.1109/tsg.2020.2968952

Publication date:

2020

Document Version

Peer reviewed version

Link back to DTU Orbit

Citation (APA):

Liu, X., Li, C., Shahidehpour, M., Chen, X., Yi, J., Wu, Q., Sun, K., \& Zhou, B. (2020). Fault Current Mitigation and Voltage Support Provision by Microgrids with Synchronous Generators. IEEE Transactions on Smart Grid, 11(4), 2816 - 2831. https://doi.org/10.1109/tsg.2020.2968952

\section{General rights}

Copyright and moral rights for the publications made accessible in the public portal are retained by the authors and/or other copyright owners and it is a condition of accessing publications that users recognise and abide by the legal requirements associated with these rights.

- Users may download and print one copy of any publication from the public portal for the purpose of private study or research.

- You may not further distribute the material or use it for any profit-making activity or commercial gain

- You may freely distribute the URL identifying the publication in the public portal 


\title{
Fault Current Mitigation and Voltage Support Provision by Microgrids with Synchronous Generators
}

\author{
Xubin Liu, Student Member, IEEE, Canbing Li, Senior Member, IEEE, Mohammad Shahidehpour, \\ Fellow, IEEE, Xinyu Chen, Member, IEEE, Jun Yi, Member, IEEE, Qiuwei Wu, Senior Member, IEEE, \\ Kai Sun, Senior Member, IEEE, Bin Zhou, Senior Member, IEEE
}

\begin{abstract}
Considering different attributes of fault current injected by inverter-based distributed generators (IBDGs) and synchronous generators (SGs) in a microgrid (MG), we propose a fault current mitigation (FCM) strategy to respond to the increasing fault current challenge during the voltage support provided by MG. Considering the impact of SGs in MGs, our proposed strategy consists of three parts: 1) a phase angle shifting (PAS) strategy is formulated to manage fault currents introduced by IBDG, SG and utility gird; 2) a power/current sharing (PCS) strategy is developed among IBDGs to match the function of PAS; 3) an inverter current generation (ICG) strategy is formulated considering network impedance features that provides a better voltage support performance. Several tests are performed and the results are analyzed to validate the effectiveness of the proposed strategy in which the MG fault current poses the minimum effect on the system fault current as MG provides voltage support with both IBDGs and SGs.
\end{abstract}

Index Terms-Distributed generator, microgrid, fault current mitigation, inverter, voltage support.

\section{NOMENCLATURE}

$\begin{array}{ll}\text { Abbreviations } & \\ \text { MG } & \text { Microgrid } \\ \text { UG } & \text { Utility grid } \\ \text { IBDG } & \text { Inverter-based distributed generator } \\ \text { SG } & \text { Synchronous generator } \\ \text { FCM } & \text { Fault current mitigation } \\ \text { PCS } & \text { Power/current sharing } \\ \text { PAS } & \text { Phase angle shifting } \\ \text { ICG } & \text { Inverter current generation } \\ \text { PCC } & \text { Point of common coupling }\end{array}$

This work was supported in part by the Open Fund of State Key Laboratory of Power Grid Safety and Energy Conservation (China Electric Power Research Institute) under Grant FXB51201801463, in part by the National Natural Science Foundation of China under Grant 51722701, 51907066, and in part by Wuhan Nari Limited Liability Company of State Grid Electric Power Research Institute under Grant 20191340. (Corresponding author: Canbing Li)

$X$. Liu is with the College of Electric and Information Engineering, Hunan University, Changsha 410082, China, with the State Key Laboratory of Power Grid Safety and Energy Conservation, Electric Power Research Institute, Beijing 100192, China, and also with the School of Electrical and Electronic Engineering, HUST, Wuhan 430074, China (e-mail: xbliu@ @nu.edu.cn). C. Li is with the School of Electronic Information and Electrical Engineering, Shanghai Jiaotong University, Shanghai 200240, China (e-mail: licanbing@ @jtu.edu.cn). B Zhou is with the College of Electric and Information Engineering, Hunan University, Changsha 410082, China (e-mail: binzhou@hnu.edu.cn). M. Shahidehpour is with the Electrical and Computer Engineering Department, Illinois Institute of Technology, Chicago, IL 60616 USA (e-mail: ms@iit.edu). $\mathrm{He}$ is also a Research Professor with the Center of Research Excellence in Renewable Energy and Power Systems, King Abdulaziz University, Jeddah, 21589, Saudi Arabia. X. Chen is with the School of Electrical and Electronic Engineering, HUST, Wuhan 430074, China (e-mail: xchen2019@ hust.edu.cn). J. $\mathrm{Yi}$ is with the State Key Laboratory of Power Grid Safety and Energy Conservation, Electric Power Research Institute, Beijing 100192, China (e-mail: yjun@epri.sgcc.com.cn). Q. Wu is with the Center for Electric Power and Energy (CEE), Department of Electrical Engineering, Technical University of Denmark (DTU), Lyngby, Denmark (e-mail: qw@elektro.dtu.dk). K. Sun is with the State Key Laboratory of Power Systems, Department of Electrical Engineering, Tsinghua University, Beijing 100084, China (e-mail: sun-kai@mail.tsinghua.edu.cn).

\begin{tabular}{|c|c|}
\hline \multicolumn{2}{|c|}{ Indices and superscripts } \\
\hline,+- & Positive and negative sequence \\
\hline$\alpha, \beta$ & Variables in stationary reference frame \\
\hline$q, p$ & Reactive and active current/power \\
\hline$n, M$ & $m^{\text {th }}$ IBDG, total number of IBDGs \\
\hline$n, N$ & $n^{\text {th }} \mathrm{SG}$, total number of SGs \\
\hline$g$ & UG \\
\hline$T$ & Total uncontrollable fault current \\
\hline$w$ & New state of variables after PAS \\
\hline$a, b, c$ & Current/voltage in phase-a, phase-b, phase-c \\
\hline * & Reference value \\
\hline$\wedge$ & Amplitude value \\
\hline \multicolumn{2}{|c|}{ Parameters and variables } \\
\hline$C_{l}, C_{m}, C_{M}$ & $\begin{array}{l}\text { Nameplate capacity of } I^{\text {th }}, m^{\text {th }} \text { and } M^{\text {th }} \text { IBDG's } \\
\text { inverter }\end{array}$ \\
\hline$v_{\alpha}^{+}, v_{\beta}^{+}, v_{\alpha}^{-}, v_{\beta}^{-}$ & Positive/negative sequence voltage in $\alpha$ - $\beta$ frame \\
\hline & $\begin{array}{l}\text { Initial phase angle of positive/negative sequence } \\
\text { voltage }\end{array}$ \\
\hline$\omega$ & UG angular frequency \\
\hline$V^{+}, V^{-}$ & $\begin{array}{l}\text { Positive/negative sequence PCC voltage } \\
\text { amplitude }\end{array}$ \\
\hline$v^{+}, v^{-}$ & Positive and negative sequence voltage vector \\
\hline$v_{\perp}^{+}, v_{\perp}^{-}$ & Corresponding orthogonal vector of $v^{+}$and $v^{-}$ \\
\hline$k q, k_{p}$ & Adjustable coefficients of reactive/active current \\
\hline$I_{\operatorname{maxm}}^{*}$ & Maximum output current of the $m^{\text {th }}$ inverter \\
\hline$I_{\text {limitm }}$ & Prescribed threshold value of $I_{\text {maxm }}^{*}$ \\
\hline$\gamma_{p}, \gamma_{R}$ & Proportional gain and resonant gain \\
\hline$\omega$ & Cutoff frequency \\
\hline
\end{tabular}

\section{INTRODUCTION}

$\mathrm{D}$ RIVEN by the abundance of natural resources, energy shortages in developing countries, environmental concerns, and economic issues, renewable energy sources combined with conventional sources (e.g., microturbines) are massively integrated into the utility grid (UG) to form MGs [1]. MG is usually viewed as a cluster of DGs, which are classified into two types: inverter-based distributed generators (IBDGs) which include wind turbines, photovoltaic arrays, fuel cells and energy storage systems; and synchronous generators (SGs) which are integrated directly into UG, including small-scale water turbines, gas turbines and diesel generators. Using local DGs, MGs could play a crucial role by providing voltage support during UG faults which can improve the efficiency and reliability of UG [2].

During UG faults, MGs act accordingly from islanding to fault ride-through and the provision of voltage support, which can strengthen the MG immunity against voltage sags and unplanned islanding [3]-[4]. MG voltage support in a UG fault, injects IBDG and SG current along with UG fault current into the fault branch. Thus, the branch fault current will rise sharply due to the integration of MG.

However, it is imperative to review the challenges posed by MGs concerning large UG fault currents. 1) Fault current management: static devices including transmission lines and transformers [5], and protective devices including circuit 
breakers, fuses, and reclosers [6] are designed to afford UG fault currents. However, extra injected MG fault currents could cause existing devices to be more vulnerable to UG faults, leading to higher maintenance, especially in aging electricity infrastructures. If this potential risk persists, the MG integration may be restricted by UG operators [7]. 2) Mitigation of fault current: Potentially higher network losses, lower power quality, and concerns with MG system stability and reliability may exacerbate the UG fault clearing process and cause cascading UG outages in extreme cases [1].

Extensive research has been conducted to deal with the MG fault current while it provides voltage support. One solution is to install auxiliary equipment at PCC including a solid-state and magnetic fault current limiter (FCL) [8]-[9] which would increase the MG network impedance during UG faults. However, FCL will add to the MG cost of integration and operation, including the cost of energy losses [9]. In addition, FCL can only reduce but cannot eliminate the impact of IBDG fault current on the UG fault current, and hence, a widespread application of FCL in power systems will take a relatively long time.

Another solution which does not require any additional equipment installation will act upon IBDGs during UG fault conditions. IBDGs are simply islanded according to the IEEE Standard 1547 once UG faults occur [10]. A capacity threshold considering the numbers and the locations of IBDGs is presented in [11]. The IBDG current limitation pertaining to $\mathrm{MG}$ voltage conditions is proposed in [12]-[14]. Accordingly, the phase angle is shifted to weaken the impact of IBDG fault current [9].

Most of the existing UG fault current limitation practices focus on MGs with only IBDG units. Among DG options, SGs provide the largest fault current because of its rigidity attributes. In addition it is important to analyze various DG types for UG fault current management since MGs often include both IBDGs and SGs [3], [15]-[18]. The total fault current limitation requires a comprehensive analysis of $\mathrm{UG}$ and $\mathrm{MG}$ fault currents. For minimizing the impact of MG fault current on the total fault current, we propose a phase angle shifting (PAS) strategy for IBDGs considering the influence of SG fault currents.

During UG fault conditions, MG voltage support requirements include voltage regulation capability, injected current quality, dc voltage ripple reduction, and minimal power oscillations [19]-[21]. The voltage support performance depends on injected $\mathrm{MG}$ current and $\mathrm{UG}$ network impedance. The network impedance is deemed as pure inductive in medium/high-voltage grids [22], pure resistive in low-voltage grids [23], and a combination in a mesh grid [3]-[4]. The network impedance calculation is analyzed in [24], [25].

In order to further improve the compensation performance of PCC voltage and maintain the injected current quality at a satisfactory level, we develop an inverter current generation (ICG) strategy that combines injected current and network impedance features. In addition, considering that the unbalanced fault voltage sag will increase IBDG peak currents, which may threaten safe MG operations [12]-[14], we develop the peak current limitation (PCL) based on the proposed ICG strategy.

In this paper, we introduce a method for providing the voltage support to MGs with IBDGs and SGs that minimizes the impact of MG current on the amplitude of the total fault current. An FCM strategy is proposed in which: 1) The PAS strategy is formulated to mitigate IBDG fault currents considering the effect of SGs; 2) The PCS strategy is developed for calculating the IBDG power/current considering the PAS function; 3) The
ICG strategy is formulated using the network impedance and the PCL is developed accordingly.

The rest of paper is organized as follows. The system fault current analyses during MG voltage support are analyzed in Section II. The FCM strategy is described in Section III. Comparative studies for MG voltage support without/with FCM are provided in Section IV. The conclusion is made in Section V.

\section{FAULT CURRENT ANALYSES DURING MG VOLTAGE SUPPORT WITH IBDGS AND SGS}

During MG voltage support in UG fault conditions, the system total branch fault current is contributed by both MG fault current and UG fault current. Here, we analyze controllable and uncontrollable components of the total fault current.

\section{A. Fault Current Flow Analyses}

The UG-connected MG topology and the corresponding fault currents flow are shown in Fig. 1. IBDGs are connected to UG through a full power inverter. The inverter is equipped with a $L C L$ filter to reduce high frequency noise and switching harmonics. The IBDG and SG are integrated in MG and MG is connected to UG at PCC. The $R_{g}, L_{g}$ and $R_{l}, L_{l}$ are the network impedance between $\mathrm{UG}$ and MG to the fault bus, respectively. $I_{g}$, $I_{M G}$ and $\theta_{g}, \theta_{M G}$ are the amplitude and phase angle of UG and MG fault currents, respectively. $I_{m}, I_{n}$ and $\theta_{m}, \theta_{n}$ are the amplitude and phase angle of IBDG and SG fault currents, respectively. $I_{S}$ and $\theta_{S}$ are the amplitude and the phase angle of the system total branch fault current. Here, the fault occurs at a UG bus that is located outside MG. The total fault current includes those of UG and MG.

\section{B. Fault Current Attributes Analyses}

Inside MGs, both IBDGs and SGs are classified based on whether they are dc-isolated by inverters when they are integrated to UG. The attributes of fault current injected by DGs are shown in Table I which should be considered before mitigation.

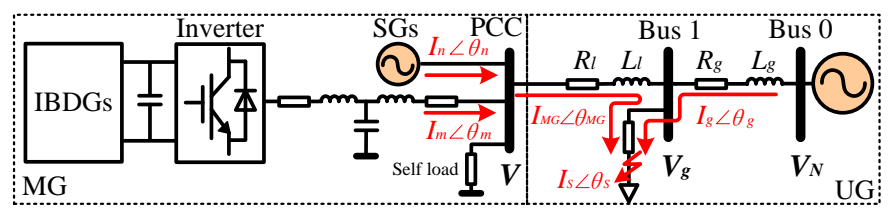

Fig. 1. Topology of UG-connected MG and the corresponding fault currents.

\begin{tabular}{|c|c|c|c|c|c|}
\hline $\begin{array}{c}\text { DG } \\
\text { Types } \\
\end{array}$ & Examples & $\begin{array}{c}\mathrm{DC} \\
\text { isolation }\end{array}$ & $\begin{array}{c}\text { DG } \\
\text { attributes } \\
\end{array}$ & $\begin{array}{c}\text { Fault current } \\
\text { attributes }\end{array}$ & $\begin{array}{c}\text { Fault current } \\
\text { impact } \\
\end{array}$ \\
\hline IBDG & $\begin{array}{l}\text { Wind, solar, fuel cell, } \\
\text { energy storage, et al }\end{array}$ & Yes & $\begin{array}{c}\text { Non inertial } \\
{[26]-[27]}\end{array}$ & $\begin{array}{c}\text { Adjustable } \\
{[9]}\end{array}$ & Controllable \\
\hline SG & $\begin{array}{l}\text { Water turbine, gas } \\
\text { turbine, and diesel } \\
\text { generator, et al }\end{array}$ & No & $\begin{array}{c}\text { Inertial } \\
{[26]-[27]}\end{array}$ & $\begin{array}{c}\text { Synchronous } \\
{[26]-[27]}\end{array}$ & Uncontrollable \\
\hline
\end{tabular}

\section{Fault Current Mitigation Analyses}

In Fig. 1, the total branch fault current is injected by UG, SG and IBDG fault currents during MG voltage support. Among these fault currents, IBDG fault current has two controllable parameters including amplitude and phase angle. Considering a constant amplitude, the phase angle of IBDG fault current is controlled to minimize the impact of MG fault current on the total fault current. Considering SGs, the fault current injection without/with any mitigation is shown in Fig. 2.

In Fig. 2(a), the worst scenario occurs when the IBDG fault current has the same phase angle as that of total uncontrollable 
fault current. In Fig. 2(b), the optimal scenario occurs when the IBDG fault current has a certain phase angle difference with uncontrollable fault current. The IBDG fault current can be mitigated by phase angel shifting, with a minimum effect on total fault current, since the amplitude of total fault current is equal to that of the uncontrollable fault current. Based on this concept, we determine the desirable phase angle of IBDG fault current to minimize the effect of MG fault current on the total fault current.

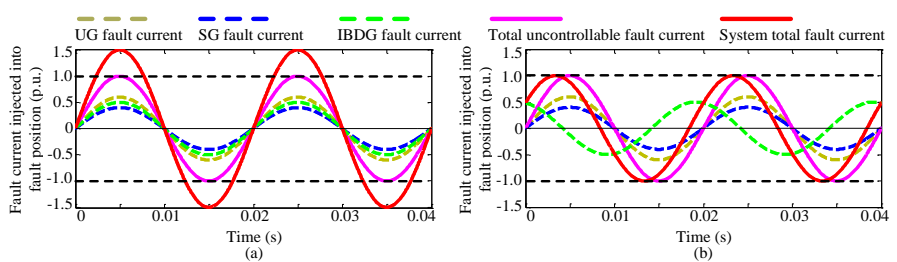

Fig. 2. Fault current injection: (a) without mitigation, (b) with mitigation.

For fault current management, the main difference between amplitude control (e.g., FCL and peak current limiting) and phase control (e.g., fault current mitigation) to regulate the impact of IBDG fault current is summarized as: 1) Using the amplitude control, the impact of IBDG fault current can only be mitigated when IBDG is disconnected. Meanwhile, this may cause an MG voltage support failure if the current is insufficient. As long as DG is UG-connected, it will increase the amplitude of the total fault current; 2) Using the phase control, the provision of PAS strategy can mitigate the impact of IBDG fault current even if IBDG is UG-connected. Meanwhile, the MG voltage support is not affected by fault current mitigation.

\section{Fault Current Influence Analyses}

The main impacts of MG fault current mitigation on UG operations are listed as follows:

1) MG Selectivity: The MG penetration increases the total fault current amplitude. For the sake of security, MG should not be integrated into vulnerable or aging UGs because MG fault current cannot be much increased. However, the mitigation of MG fault current improves the UG's fault current management, since the IBDG fault current has no impact on the total fault current amplitude. Accordingly, the UG equipment does not need to be updated frequently to cope with the growing fault current. Therefore, the selectivity of the location and the size of MG integration can improve the UG operation.

2) Coordination: With the use of larger interconnected power grids and higher voltage levels, UG is experiencing sharper rises in fault currents. The mitigation of MG fault current in coordination with UGs provides additional fault current safety margins.

3) Relay Protection: The addition of MGs could make the total fault current closer to relay ratings, which can cause serious protection problems. Even if the total fault current does not surpass the ratings, the coordination between primary and secondary protective devices can be disturbed due to the addition of MG fault current. The mitigation of MG fault current is conducive to fault removal and safe operations of relays in UG.

4) Clean Energy Integration: The variability of clean energy hinders its use for power balancing. The use of energy storage and strengthening power grid interconnections are considered as two best solutions in such cases. However, both solutions will increase the UG fault current amplitude which could restrict large integrations of clean energy. The mitigation of MG fault current can improve the integration of clean energy.

\section{FAUlt CURRENT Mitigation StRATEgy FOR MG VOLTAGE SUPPORT WITH IBDGS AND SGS}

The MG voltage support is determined by local DG behavior. We propose the application of FCM strategy, which consists of PAS, PCS, and ICG for IBDG control with the consideration of SGs.

\section{A. PAS Strategy}

The PAS strategy is formulated to mitigate the effect of IBDG fault currents on system total fault current. In Fig. 1, during MG voltage support with IBDGs and SGs, the total fault current is injected by total uncontrollable and controllable fault currents. The former is contributed by UG and SG fault currents, and the latter is contributed by IBDG fault current. The effect of MG fault current on the total fault current depends on two controllable parameters of IBDG fault current including the amplitude and the phase angle. In this case, the effect depends on phase angle as we consider constant amplitude.

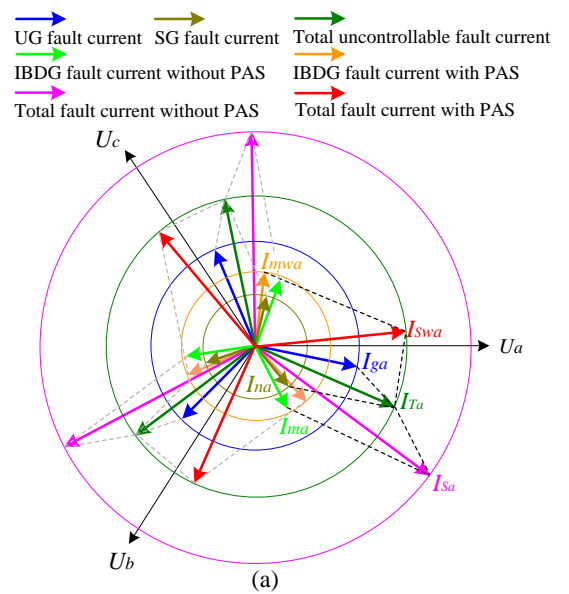

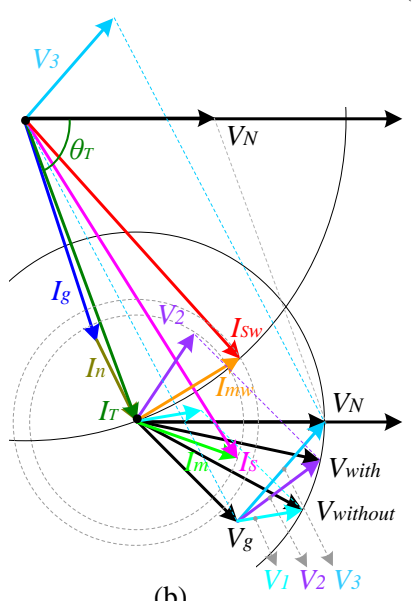

(b)

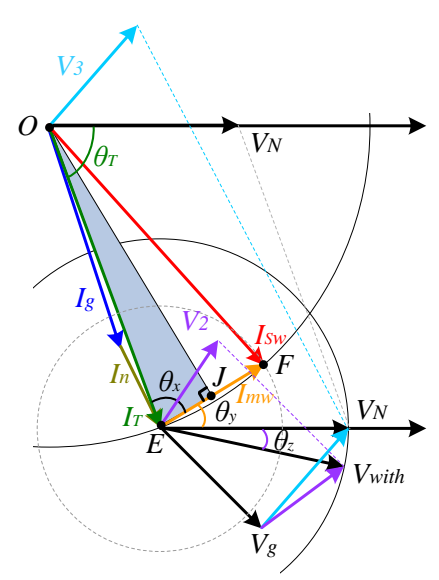

(c)
Fig. 3. Fault current phasors without/with PAS strategy.

The phasor illustration of fault currents without/with PAS is shown in Fig. 3. Since the PAS principle for positive and negative sequence currents is the same, we do not show both sequences in Fig. 3. Taking phase- $a$ as an example, in Fig. 3(a), the synthesis of UG fault current $\left(I_{g a}\right)$ and SG fault current $\left(I_{n a}\right)$ is the total uncontrollable fault current $\left(I_{T a}\right)$. In the case without PAS, the IBDG fault current is $I_{m a}$, and the total fault current is $I_{S a}$. In the case with PAS, the IBDG fault current is shifted to $I_{m w a}$, thus the total fault current becomes $I_{S w a}$. It is obvious that the amplitude of $I_{S a}$ is much larger than that of $I_{T a}$, while the amplitude of $I_{S w a}$ is equal to that of $I_{T a}$. Based on Fig. 3(a), Fig. 3(b) shows the corresponding positive sequence phasor. The 
variable after deleting the subscript "a" corresponds to the principle in Fig. 3 (a).

In Fig. 3(b), and based on the topology in Fig. 1, the vectors $V_{N}, V_{\text {with }}, V_{\text {without }}, V_{g}$ are normal voltages at UG's BusO, supported voltage at PCC with PAS, supported voltage at PCC without PAS, and fault voltage at $B u s 1$, respectively. The vectors $V_{l}, V_{2}$, $V_{3}$ are voltages on line impedances between PCC and Busl without PAS, between PCC and Bus 1 with PAS, between $\mathrm{BusO}$ and Busl. In this paper, $V_{N}$ is set as the reference angle. The angle relationship is shown in Fig. 3(c). The $\theta_{x}, \theta_{y}, \theta_{z}$ are the bottom angle of the isosceles triangle $O E F$, the angle between $V_{N}$ and $I_{m w}$, the angle between $V_{N}$ and $V_{\text {with }}$. Then, $\theta_{m w}$, which is equal to $\theta_{y}$ plus $\theta_{z}$, is the desirable phase angle for the PAS strategy. In this way, based on $\theta_{m w}$, the effect of IBDG fault current on the total fault current is almost mitigated, and the MG fault current has a minimum effect on the amplitude of the total fault current.

The PAS strategy will not affect the function of voltage support, as shown in phasor relationship in Fig. 3(b):

1) The MG voltage support requires a relatively large line impedance between PCC and fault Busl to effectively boost PCC voltage. In practice, MG might be remotely located in UG. Taking $V_{N}$ angle as the reference, the phase angle of supported PCC voltage at UG would lag that, e.g., $V_{\text {with }}$ and $V_{\text {without }}$ lag $V_{N}$. 2) During voltage support, both MG and UG inject fault current, and voltage phase angles at PCC and BusO lead that at Busl, e.g., $V_{N}$ leads $V_{\text {with }}$ and $V_{\text {without }}$, while $V_{\text {with }}$ and $V_{\text {without }}$ lead $V_{g}$. Also, the $V_{g}$ amplitude is less than that of $V_{N}$, and amplitudes of $V_{\text {with }}$ and $V_{\text {without }}$ are equal to that of $V_{N}$.

3) Assuming that the fault voltage sag is constant, the amplitude and phase angle of supported PCC voltage will vary with IBDG current's phase angle and amplitude, e.g., $V_{\text {with }}$ leads $V_{\text {without }}$.

4) Under the same fault condition, the amplitude of UG fault current is larger than that of MG fault current, e.g. the amplitude of $I_{g}$ is larger than those of $I_{m}$ and $I_{m w}$.

5) The line impedance is resistive/inductive, thus the voltage on the line impedance must lead the corresponding current, e.g., $V_{l}$ leads $I_{m}, V_{2}$ leads $I_{m w}$, and $V_{3}$ leads $I_{g}$. The $I_{m}, I_{m w}, I_{g}$ are inductive currents. For voltage support, the current angle cannot be chosen arbitrarily since the angle between $V_{l}$ and $I_{m}$ and the angle between $V_{2}$ and $I_{m w}$ should be equal to the line impedance angle. When the line impedance angle is small/large, the phase angel of IBDG current may lead/lag PCC voltage [3], [28]. In Fig. 3(b), considering a small line impedance angle, it is reasonable that $I_{m}$ leads $V_{\text {without }}$, and $I_{m w}$ leads $V_{\text {with }}$. However, this does not affect the basic principle of voltage support by reactive power compensation [3],[16],[19],[28].

6) During voltage support, the PAS of IBDG current can be compensated by increasing the amplitude, e.g., the amplitude of $I_{m w}$ is larger than that of $I_{m}$ (see Section IV. E).

Considering the SG influence, the vector of total uncontrollable fault current in positive/negative sequences is

$$
\vec{I}_{g}^{+/-}+\sum_{n=1}^{N} \vec{I}_{n}^{+/-}=\vec{I}_{T}^{+/-} .
$$

The relationship of (1) can be described as

$$
\begin{aligned}
& \hat{I}_{g}^{+/-} \cos \left(\theta_{g}^{+/-}\right)+\sum_{n=1}^{N} \hat{I}_{n}^{+/-} \cos \left(\theta_{n}^{+/-}\right)=\hat{I}_{T}^{+/-} \cos \left(\theta_{T}^{+/-}\right) \\
& \hat{I}_{g}^{+/-} \sin \left(\theta_{g}^{+/-}\right)+\sum_{n=1}^{N} \hat{I}_{n}^{+/-} \sin \left(\theta_{n}^{+/-}\right)=\hat{I}_{T}^{+/-} \sin \left(\theta_{T}^{+/-}\right)
\end{aligned}
$$

Based on (2), the amplitude and the phase angle of total uncontrollable fault current is obtained as
$\hat{I}_{T}^{+/-}=$

$\sqrt{\left(\hat{I}_{g}^{+/-}\right)^{2}+\left[\sum_{n=1}^{N} \hat{I}_{n}^{+/-} \sin \left(\theta_{n}^{+/-}\right)\right]^{2}+\left[\sum_{n=1}^{N} \hat{I}_{n}^{+/-} \cos \left(\theta_{n}^{+/-}\right)\right]^{2}+2 \hat{I}_{g}^{+/-} \sum_{n=1}^{N} \hat{I}_{n}^{+/-} \cos \left(\theta_{g}^{+/-}-\theta_{n}^{+/-}\right)}$

$\theta_{T}^{+/-}=$

$\cos ^{-1}\left[\frac{\hat{I}_{g}^{+/-} \cos \left(\theta_{g}^{+/-}\right)+\sum_{n=1}^{N} \hat{I}_{n}^{+/-} \cos \left(\theta_{n}^{+/-}\right)}{\hat{I}_{T}^{+/-}}\right]$

In order to mitigate the IBDG fault current, the vector of total fault current is expressed as

$$
\vec{I}_{T}^{+/-}+\sum_{m=1}^{M} \vec{I}_{m w}^{+/-}=\vec{I}_{S w}^{+/-} .
$$

The amplitude relationship in (4) is restated as

$$
\left\{\begin{array}{l}
\hat{I}_{m w}^{+/-}=\hat{I}_{m}^{+/-} \\
\hat{I}_{S w}^{+/-}=\hat{I}_{T}^{+/-}
\end{array}\right. \text {. }
$$

Based on (5), we state (4) as

$$
\begin{aligned}
& \hat{I}_{T}^{+/-} \cos \left(\theta_{T}^{+/-}\right)+\sum_{m=1}^{M} \hat{I}_{m}^{+/-} \cos \left(\theta_{m w}^{+/-}\right)=\hat{I}_{T}^{+/-} \cos \left(\theta_{S w}^{+/-}\right) \\
& \hat{I}_{T}^{+/-} \sin \left(\theta_{T}^{+/-}\right)+\sum_{m=1}^{M} \hat{I}_{m}^{+/-} \sin \left(\theta_{m w}^{+/-}\right)=\hat{I}_{T}^{+/-} \sin \left(\theta_{S w}^{+/-}\right)
\end{aligned}
$$

Using (6), the IBDG fault current is

$$
\left\{\begin{array}{l}
\sum_{m=1}^{M} \hat{I}_{m}^{+/-} \cos \left(\theta_{m w}^{+/-}\right)=\hat{I}_{T}^{+/-}\left[\cos \left(\theta_{S w}^{+/-}\right)-\cos \left(\theta_{T}^{+/-}\right)\right] \\
\sum_{m=1}^{M} \hat{I}_{m}^{+/-} \sin \left(\theta_{m w}^{+/-}\right)=\hat{I}_{T}^{+/-}\left[\sin \left(\theta_{S w}^{+/-}\right)-\sin \left(\theta_{T}^{+/-}\right)\right]
\end{array} .\right.
$$

Based on (7) and the geometric relationship in Fig. 3(c), the following angle relationship exists:

$$
\begin{aligned}
& \theta_{T}^{+/-}+\theta_{x}^{+/-}+\theta_{y}^{+/-}=\pi \\
& \theta_{x}^{+/-}=\cos ^{-1}\left(\frac{\hat{I}_{m}^{+-}}{2 \hat{I}_{T}^{+/-}}\right) \\
& \theta_{m w}^{+/-}=\theta_{y}^{+/-}+\theta_{z}^{+/-} \\
& \hat{I}_{m}^{+/-}=\hat{I}_{m w}^{+l-}
\end{aligned} .
$$

The relationship of first row in (8) is because the sum of the internal angles between parallel lines is $\pi$. The relationship of second row in (8) is calculated using the isosceles triangles geometric theory. Based on Fig. 3(c), the region $O E F$ is a isosceles triangles, since $O E=O F$. Then, because the height of isosceles triangle divides the base side into halves, we obtain the length relationship of $E J=J F$. Thus, $E J=\frac{E F}{2}=\frac{\hat{I}_{m}^{+/-}}{2}$. Since the length of hypotenuse $O E$ is $\hat{I}_{T}^{+/-}, \theta_{x}^{+/-}$can be calculated based on the trigonometric function, as shown in second row in (8). The relationship of third row in (8) is because $\theta_{m w}^{+/-}$is the angle between IBDG current and PCC voltage.

Thus, the phase angle of $m^{\text {th }}$ IBDG fault current is obtained as

$$
\theta_{m w}^{+/-}=\pi-\theta_{T}^{+/-}-\cos ^{-1}\left(\frac{\hat{I}_{m}^{+/-}}{2 \hat{I}_{T}^{+/-}}\right)+\theta_{z}^{+/-} .
$$

Considering the phase angle shifting for mitigation, the current and the angle have the following relationship

$$
\hat{I}_{m}^{+/-}=\frac{\hat{I}_{m q}^{+/-}}{\sin \left(\theta_{m w}^{+/-}\right)} .
$$

Based on (10), (9) is modified as

$$
\theta_{m w}^{+/-}=\pi-\theta_{T}^{+/-}-\cos ^{-1}\left(\frac{\hat{I}_{m q}^{+/-}}{2 \hat{I}_{T}^{+/-} \sin \left(\theta_{m w}^{+/-}\right)}\right)+\theta_{z}^{+/-} .
$$

By mathematical analysis, (11) is rewritten as 


$$
\begin{aligned}
\frac{I_{m q}^{+/-}}{2 \hat{I}_{T}^{+/-}} & =\sin \left(\theta_{m w}^{+/-}\right) \cos \left(\pi-\theta_{T}^{+/-}+\theta_{z}^{+/-}-\theta_{m w}^{+/-}\right) \\
& =\frac{1}{2}\left[\sin \left(\pi-\theta_{T}^{+/-}+\theta_{z}^{+/-}\right)+\sin \left(2 \theta_{m w}^{+/-}+\theta_{T}^{+/-}-\theta_{z}^{+/-}-\pi\right)\right]
\end{aligned}
$$

Then, (12) is rewritten as

$$
2 \theta_{m w}^{+/-}+\theta_{T}^{+/-}-\theta_{z}^{+/-}-\pi=\sin ^{-1}\left[\frac{I_{m q}^{+/-}}{\hat{I}_{T}^{+/-}}-\sin \left(\pi-\theta_{T}^{+/-}+\theta_{z}^{+/-}\right)\right] .
$$

Using (13), the PAS strategy considering SGs is proposed as

$$
\theta_{m w}^{+/-}=\frac{1}{2}\left\{\left(\pi-\theta_{T}^{+/-}+\theta_{z}^{+/-}\right)+\sin ^{-1}\left[\frac{I_{m q}^{+/-}}{\hat{I}_{T}^{+/-}}-\sin \left(\pi-\theta_{T}^{+/-}+\theta_{z}^{+/-}\right)\right]\right\} .
$$

\section{B. PCS Strategy}

The PCS strategy is developed for calculating the IBDG power/current to match the function of PAS strategy. In this paper, MG is connected to three-phase three-wire UG systems; thus, only positive/negative sequence components are considered. In addition, the three-phase four-wire systems with star-ungrounded transformers and three-phase four-wire systems with delta-connected transformers are suitable for our strategy since the zero-sequence component would not travel to the secondary side control system [29]. Otherwise, the additional zero-sequence control should be considered.

The PCC voltage is expressed as [4], [13]

$$
v^{+}=\left[\begin{array}{c}
v_{\alpha}^{+} \\
v_{\beta}^{+}
\end{array}\right]=\left[\begin{array}{c}
V^{+} \cos \left(\omega t+\delta^{+}\right) \\
V^{+} \sin \left(\omega t+\delta^{+}\right)
\end{array}\right], \quad v^{-}=\left[\begin{array}{c}
v_{\alpha}^{-} \\
v_{\beta}^{-}
\end{array}\right]=\left[\begin{array}{c}
V^{-} \cos \left(\omega t+\delta^{-}\right) \\
-V^{-} \sin \left(\omega t+\delta^{-}\right)
\end{array}\right] \text {. }
$$

where $V^{+}=\sqrt{\left(v_{\alpha}^{+}\right)^{2}+\left(v_{\beta}^{+}\right)^{2}}, V^{-}=\sqrt{\left(v_{\alpha}^{-}\right)^{2}+\left(v_{\beta}^{-}\right)^{2}} \quad$ subscript “ $\perp$ ” represents the orthogonal vector, and $v_{\perp}^{+}$and $v_{\perp}^{-}$are the corresponding orthogonal vectors of $v^{+}$and $v^{-}$[4], [13].

The IBDG fault current can be divided as [13]

$$
\begin{aligned}
i_{m}=i_{m p}^{+}+i_{m p}^{-}+i_{m q}^{+}+i_{m q}^{-}= & {\left[\begin{array}{c}
I_{m p}^{+} \cos \left(\omega t+\delta^{+}\right) \\
I_{m p}^{+} \sin \left(\omega t+\delta^{+}\right)
\end{array}\right]+\left[\begin{array}{c}
I_{m p}^{-} \cos \left(\omega t+\delta^{-}\right) \\
-I_{m p}^{-} \sin \left(\omega t+\delta^{-}\right)
\end{array}\right]+} \\
& {\left[\begin{array}{c}
I_{m q}^{+} \sin \left(\omega t+\delta^{+}\right) \\
-I_{m q}^{+} \cos \left(\omega t+\delta^{+}\right)
\end{array}\right]+\left[\begin{array}{c}
-I_{m q}^{-} \sin \left(\omega t+\delta^{-}\right) \\
-I_{m q}^{-} \cos \left(\omega t+\delta^{-}\right)
\end{array}\right] }
\end{aligned}
$$

The adjustment of amplitudes of $I_{m p}^{+-}$and $I_{m q}^{+/-}$can change the phase angle of IBDG fault current.

The SG fault current can be divided as [13]

$$
\begin{aligned}
i_{n}=i_{n p}^{+}+i_{n p}^{-}+i_{n q}^{+}+i_{n q}^{-}= & {\left[\begin{array}{c}
I_{n p}^{+} \cos \left(\omega t+\delta^{+}\right) \\
I_{n p}^{+} \sin \left(\omega t+\delta^{+}\right)
\end{array}\right]+\left[\begin{array}{c}
I_{n p}^{-} \cos \left(\omega t+\delta^{-}\right) \\
-I_{n p}^{-} \sin \left(\omega t+\delta^{-}\right)
\end{array}\right]+} \\
& {\left[\begin{array}{c}
I_{n q}^{+} \sin \left(\omega t+\delta^{+}\right. \\
-I_{n q}^{+} \cos \left(\omega t+\delta^{+}\right)
\end{array}\right]+\left[\begin{array}{l}
-I_{n q}^{-} \sin \left(\omega t+\delta^{-}\right) \\
-I_{n q}^{-} \cos \left(\omega t+\delta^{-}\right)
\end{array}\right] }
\end{aligned}
$$

Based on [4] and [13], and considering SGs, the PCC voltage during the fault condition is expressed as

$$
\begin{aligned}
& v_{\alpha}=\left(v_{g \alpha}^{+}+v_{g \alpha}^{-}\right)+R_{l}\left[\sum_{m=1}^{M}\left(i_{m \alpha}^{+}+i_{m \alpha}^{-}\right)+\sum_{n=1}^{N}\left(i_{n \alpha}^{+}+i_{n \alpha}^{-}\right)\right]+L_{l} \frac{d\left[\sum_{m=1}^{M}\left(i_{m \alpha}^{+}+i_{m \alpha}^{-}\right)+\sum_{n=1}^{N}\left(i_{n \alpha}^{+}+i_{n \alpha}^{-}\right)\right]}{d t} \\
& v_{\beta}=\left(v_{g \beta}^{+}+v_{g \beta}^{-}\right)+R_{l}\left[\sum_{m=1}^{M}\left(i_{m \beta}^{+}+i_{m \beta}^{-}\right)+\sum_{n=1}^{N}\left(i_{n \beta}^{+}+i_{n \beta}^{-}\right)\right]+L_{l} \frac{d\left[\sum_{m=1}^{M}\left(i_{m \beta}^{+}+i_{m \beta}^{-}\right)+\sum_{n=1}^{N}\left(i_{n \beta}^{+}+i_{n \beta}^{-}\right)\right]}{d t}
\end{aligned}
$$

Based on (15)-(17), (18) is expanded as in (19). In general, the differences between $\delta^{+}$and $\delta_{g}^{+}$and between $\delta^{-}$and $\delta_{g}^{-}$are negligible [13]. Therefore, (19) is represented as in (20).

$$
\begin{aligned}
& {\left[\begin{array}{c}
V^{+} \cos \left(\omega t+\delta^{+}\right)+V^{-} \cos \left(\omega t+\delta^{-}\right) \\
V^{+} \sin \left(\omega t+\delta^{+}\right)-V^{-} \sin \left(\omega t+\delta^{-}\right)
\end{array}\right]=\left[\begin{array}{c}
V_{g}^{+} \cos \left(\omega t+\delta_{g}^{+}\right)+V_{g}^{-} \cos \left(\omega t+\delta_{g}^{-}\right) \\
V_{g}^{+} \sin \left(\omega t+\delta^{+}\right)-V_{g}^{-} \sin \left(\omega t+\delta_{g}^{-}\right)
\end{array}\right]+} \\
& \omega L_{l}\left[\begin{array}{c}
-\left(\sum_{m=1}^{M} I_{m p}^{+}+\sum_{n=1}^{N} I_{n p}^{+}\right) \sin \left(\omega t+\delta^{+}\right)-\left(\sum_{m=1}^{M} I_{m p}^{-}+\sum_{n=1}^{N} I_{n p}^{-}\right) \sin \left(\omega t+\delta^{-}\right) \\
\left(\sum_{m=1}^{M} I_{m p}^{+}+\sum_{n=1}^{N} I_{n p}^{+}\right) \cos \left(\omega t+\delta^{+}\right)-\left(\sum_{m=1}^{M} I_{m p}^{-}+\sum_{n=1}^{N} I_{n p}^{-}\right) \cos \left(\omega t+\delta^{-}\right)
\end{array}\right]+ \\
& \omega L_{l}\left[\begin{array}{c}
\left(\sum_{m=1}^{M} I_{m q}^{+}+\sum_{n=1}^{N} I_{n q}^{+}\right) \cos \left(\omega t+\delta^{+}\right)-\left(\sum_{m=1}^{M} I_{m q}^{-}+\sum_{n=1}^{N} I_{n q}^{-}\right) \cos \left(\omega t+\delta^{-}\right) \\
\left(\sum_{m=1}^{M} I_{m q}^{+}+\sum_{n=1}^{N} I_{n q}^{+}\right) \sin \left(\omega t+\delta^{+}\right)+\left(\sum_{m=1}^{M} I_{m q}^{-}+\sum_{n=1}^{N} I_{n q}^{-}\right) \sin \left(\omega t+\delta^{-}\right)
\end{array}\right]+ \\
& R_{l}\left[\begin{array}{c}
\left(\sum_{m=1}^{M} I_{m p}^{+}+\sum_{n=1}^{N} I_{n p}^{+}\right) \cos \left(\omega t+\delta^{+}\right)+\left(\sum_{m=1}^{M} I_{m p}^{-}+\sum_{n=1}^{N} I_{n p}^{-}\right) \cos \left(\omega t+\delta^{-}\right) \\
\left(\sum_{m=1}^{M} I_{m p}^{+}+\sum_{n=1}^{N} I_{n p}^{+}\right) \sin \left(\omega t+\delta^{+}\right)-\left(\sum_{m=1}^{M} I_{m p}^{-}+\sum_{n=1}^{N} I_{n p}^{-}\right) \sin \left(\omega t+\delta^{-}\right)
\end{array}\right]+ \\
& R_{l}\left[\begin{array}{c}
\left(\sum_{m=1}^{M} I_{m q}^{+}+\sum_{n=1}^{N} I_{n q}^{+}\right) \sin \left(\omega t+\delta^{+}\right)-\left(\sum_{m=1}^{M} I_{m q}^{-}+\sum_{n=1}^{N} I_{n q}^{-}\right) \sin \left(\omega t+\delta^{-}\right) \\
-\left(\sum_{m=1}^{M} I_{m q}^{+}+\sum_{n=1}^{N} I_{n q}^{+}\right) \cos \left(\omega t+\delta^{+}\right)-\left(\sum_{m=1}^{M} I_{m q}^{-}+\sum_{n=1}^{N} I_{n q}^{-}\right) \cos \left(\omega t+\delta^{-}\right)
\end{array}\right]
\end{aligned}
$$

$$
\begin{aligned}
& {\left[\begin{array}{c}
\left(V^{+}-V_{g}^{+}\right) \cos \left(\omega t+\delta^{+}\right)+\left(V^{-}-V_{g}^{-}\right) \cos \left(\omega t+\delta^{-}\right) \\
\left(V^{+}-V_{g}^{+}\right) \sin \left(\omega t+\delta^{+}\right)-\left(V^{-}-V_{g}^{-}\right) \sin \left(\omega t+\delta^{-}\right)
\end{array}\right]=} \\
& {\left[\begin{array}{c}
{\left[\omega L_{l}\left(\sum_{m=1}^{M} I_{m q}^{+}+\sum_{n=1}^{N} I_{n q}^{+}\right)+R_{l}\left(\sum_{m=1}^{M} I_{m p}^{+}+\sum_{n=1}^{N} I_{n p}^{+}\right)\right] \cos \left(\omega t+\delta^{+}\right)} \\
{\left[\omega L_{l}\left(\sum_{m=1}^{M} I_{m q}^{+}+\sum_{n=1}^{N} I_{n q}^{+}\right)+R_{l}\left(\sum_{m=1}^{M} I_{m p}^{+}+\sum_{n=1}^{N} I_{n p}^{+}\right)\right] \sin \left(\omega t+\delta^{+}\right)}
\end{array}\right]+} \\
& {\left[\begin{array}{c}
{\left[-\omega L_{l}\left(\sum_{m=1}^{M} I_{m q}^{-}+\sum_{n=1}^{N} I_{n q}^{-}\right)+R_{l}\left(\sum_{m=1}^{M} I_{m p}^{-}+\sum_{n=1}^{N} I_{n p}^{-}\right)\right] \cos \left(\omega t+\delta^{-}\right)} \\
-\left[-\omega L_{l}\left(\sum_{m=1}^{M} I_{m q}^{-}+\sum_{n=1}^{N} I_{n q}^{-}\right)+R_{l}\left(\sum_{m=1}^{M} I_{m p}^{-}+\sum_{n=1}^{N} I_{n p}^{-}\right)\right] \sin \left(\omega t+\delta^{-}\right)
\end{array}\right]+} \\
& {\left[\begin{array}{c}
{\left[-\omega L_{l}\left(\sum_{m=1}^{M} I_{m p}^{+}+\sum_{n=1}^{N} I_{n p}^{+}\right)+R_{l}\left(\sum_{m=1}^{M} I_{m q}^{+}+\sum_{n=1}^{N} I_{n q}^{+}\right)\right] \sin \left(\omega t+\delta^{+}\right)} \\
{\left[\omega L_{l}\left(\sum_{m=1}^{M} I_{m p}^{+}+\sum_{n=1}^{N} I_{n p}^{+}\right)-R_{l}\left(\sum_{m=1}^{M} I_{m q}^{+}+\sum_{n=1}^{N} I_{n q}^{+}\right)\right] \cos \left(\omega t+\delta^{+}\right)}
\end{array}\right]+} \\
& {\left[\begin{array}{c}
\left.\omega \omega L_{l}\left(\sum_{m=1}^{M} I_{m p}^{-}+\sum_{n=1}^{N} I_{n p}^{-}\right)+R_{l}\left(\sum_{m=1}^{M} I_{m q}^{-}+\sum_{n=1}^{N} I_{n q}^{-}\right)\right] \cos \left(\omega t+\delta^{-}\right) \\
-\left[\omega L_{l}\left(\sum_{m=1}^{M} I_{m p}^{-}+\sum_{n=1}^{N} I_{n p}^{-}\right)+R_{l}\left(\sum_{m=1}^{M} I_{m q}^{-}+\sum_{n=1}^{N} I_{n q}^{-}\right)\right] \sin \left(\omega t+\delta^{-}\right)
\end{array}\right]}
\end{aligned}
$$

In last two rows of (20), following expressions are satisfied,

$$
\frac{\sum_{m=1}^{M} I_{m p}^{+}+\sum_{n=1}^{N} I_{n p}^{+}}{\sum_{m=1}^{M} I_{m q}^{+}+\sum_{n=1}^{N} I_{n q}^{+}}=\frac{R_{l}}{\omega L_{l}}, \quad \frac{\sum_{m=1}^{M} I_{m p}^{-}+\sum_{n=1}^{N} I_{n p}^{-}}{\sum_{m=1}^{M} I_{m q}^{-}+\sum_{n=1}^{N} I_{n q}^{-}}=-\frac{R_{l}}{\omega L_{l}}
$$

Then, the (20) is represented as,

$$
\left[\begin{array}{c}
V^{+}-V_{g}^{+} \\
V^{-}-V_{g}^{-}
\end{array}\right]=\left[\begin{array}{c}
\omega L_{l}\left(\sum_{m=1}^{M} I_{m q}^{+}+\sum_{n=1}^{N} I_{n q}^{+}\right) \\
-\omega L_{l}\left(\sum_{m=1}^{M} I_{m q}^{-}+\sum_{n=1}^{N} I_{n q}^{-}\right)
\end{array}\right]+\left[\begin{array}{c}
R_{l}\left(\sum_{m=1}^{M} I_{m p}^{+}+\sum_{n=1}^{N} I_{n p}^{+}\right) \\
R_{l}\left(\sum_{m=1}^{M} I_{m p}^{-}+\sum_{n=1}^{N} I_{n p}^{-}\right)
\end{array}\right]
$$

In order to balance the PCC voltage, the reference of positive/negative sequences of the PCC voltage is supported as

$$
\begin{aligned}
& V^{+^{*}}=V_{\text {rated }} . \\
& V^{-*}=0
\end{aligned} .
$$

A general solution of IBDG fault current in (22) is obtained as 


$$
\begin{aligned}
& I_{m q}^{+}=\frac{\omega L_{l}}{R_{l}^{2}+\left(\omega L_{l}\right)^{2}} \times\left(V^{+^{*}}-V_{g}^{+}\right)-\sum_{n=1}^{N} I_{n q}^{+} \\
& I_{m q}^{-}=\frac{-\omega L_{l}}{R_{l}^{2}+\left(\omega L_{l}\right)^{2}} \times\left(V^{-*}-V_{g}^{-}\right)-\sum_{n=1}^{N} I_{n q}^{-} \\
& I_{m p}^{+}=\frac{R_{l}}{R_{l}^{2}+\left(\omega L_{l}\right)^{2}} \times\left(V^{+^{*}}-V_{g}^{+}\right)-\sum_{n=1}^{N} I_{n p}^{+} \\
& I_{m p}^{-}=\frac{R_{l}}{R_{l}^{2}+\left(\omega L_{l}\right)^{2}} \times\left(V^{-*}-V_{g}^{-}\right)-\sum_{n=1}^{N} I_{n p}^{-}
\end{aligned}
$$

Considering the PAS function, the IBDG output current is determined as follows: 1) Calculate the reactive current by (24), and then calculate the active current based on shifted phase angel; 2) Calculate the active current by (24), and then calculate the reactive current based on shifted phase angel. However, if $\omega L_{l} /$ $\left(R_{l}^{2}+\left(\omega L_{l}\right)^{2}\right)$ is high, the active current components of (24) do not contribute significantly to voltage support. In this case, the voltage support relies on reactive current/power injection; thus we adopt 1) for reactive and active current calculations. The active current components are used to match the PAS realization. Since MG voltage support is contributed by all local IBDGs and SGs units, using (24) and considering the nameplate capacity for coordinated operation of IBDGs, the positive/negative sequences of reactive current of $m^{\text {th }}$ IBDG are formulated as

$$
\begin{aligned}
& I_{m q}^{+}=\frac{C_{m}}{C_{1}+\ldots+C_{M}} \times\left[\frac{\omega L_{l}}{R_{l}^{2}+\left(\omega L_{l}\right)^{2}} \times\left(V^{+*}-V_{g}^{+}\right)-\sum_{n=1}^{N} I_{n q}^{+}\right] \\
& I_{m q}^{-}=\frac{C_{m}}{C_{1}+\ldots+C_{M}} \times\left[\frac{-\omega L_{l}}{R_{l}^{2}+\left(\omega L_{l}\right)^{2}} \times\left(V^{-*}-V_{g}^{-}\right)-\sum_{n=1}^{N} I_{n q}^{-}\right]
\end{aligned}
$$

where $C$ is the nameplate capacity, and $C_{l}, C_{m}, C_{M}$ are the nameplate capacity of $I^{\text {th }}, m^{\text {th }}$ and $M^{\text {th }}$ IBDG's inverter. Also, the constraint in (21) can be satisfied in (25).

Base on (14) and (25) and considering PAS, the positive/ negative sequences of active current of the $m^{\text {th }}$ IBDG is formulated as

$$
\begin{gathered}
I_{m p}^{+}=\frac{I_{m q}^{+}}{\tan \left(\theta_{m w}^{+}\right)} \\
I_{m p}^{-}=\frac{I_{m q}^{-}}{\tan \left(\theta_{m w}^{-}\right)}
\end{gathered}
$$

According to [4], [13]-[14], and based on (15)-(16), when ignoring the oscillatory terms of instantaneous active/reactive power, the reference active and reactive power is formulated as

$$
\begin{aligned}
& P_{m}^{*}=\frac{3}{2}\left(v_{\alpha}^{+} i_{m \alpha}^{+}+v_{\beta}^{+} i_{m \beta}^{+}+v_{\alpha}^{-} i_{m \alpha}^{-}+v_{\beta}^{-} i_{m \beta}^{-}\right)=\frac{3}{2}\left(V^{+} I_{m p}^{+}+V^{-} I_{m p}^{-}\right) \\
& Q_{m}^{*}=\frac{3}{2}\left(-v_{\alpha}^{+} i_{m \beta}^{+}+v_{\beta}^{+} i_{m \alpha}^{+}-v_{\alpha}^{-} i_{m \beta}^{-}+v_{\beta}^{-} i_{m \alpha}^{-}\right)=\frac{3}{2}\left(V^{+} I_{m q}^{+}+V^{-} I_{m q}^{-}\right)
\end{aligned}
$$

\section{ICG Strategy}

The ICG strategy is proposed by considering the network impedance for providing a better voltage support performance. In order to realize the flexible control of active and reactive currents of IBDG for voltage support, the existing ICG strategy is expressed as [13]-[14]

$$
\begin{array}{ll}
i_{m p}^{+*}=k_{p} \frac{2}{3} \frac{P_{m}^{*}}{\left(V^{+}\right)^{2}} v^{+}, & i_{m p}^{-*}=\left(1-k_{p}\right) \frac{2}{3} \frac{P_{m}^{*}}{\left(V^{-}\right)^{2}} v^{-} \\
i_{m q}^{+*}=k_{q} \frac{2}{3} \frac{Q_{m}^{*}}{\left(V^{+}\right)^{2}} v_{\perp}^{+}, & i_{m q}^{-*}=\left(1-k_{q}\right) \frac{2}{3} \frac{Q_{m}^{*}}{\left(V^{-}\right)^{2}} v_{\perp}^{-}
\end{array}
$$

Based on (28), the ICG strategy is proposed as

$$
\begin{aligned}
& i_{m p}^{+*}=k_{p} \frac{R}{\sqrt{R^{2}+X^{2}}} \frac{2}{3} \frac{P_{m}^{*}}{\left(V^{+}\right)^{2}} v^{+}, \quad i_{m p}^{-*}=\left(1-k_{p} \frac{R}{\sqrt{R^{2}+X^{2}}}\right) \frac{2}{3} \frac{P_{m}^{*}}{\left(V^{-}\right)^{2}} v^{-} \\
& i_{m q}^{+*}=k_{q} \frac{X}{\sqrt{R^{2}+X^{2}}} \frac{2}{3} \frac{Q_{m}^{*}}{\left(V^{+}\right)^{2}} v_{\perp}^{+}, \quad i_{m q}^{-*}=\left(1-k_{q} \frac{X}{\sqrt{R^{2}+X^{2}}}\right) \frac{2}{3} \frac{Q_{m}^{*}}{\left(V^{-}\right)^{2}} v_{\perp}^{-}
\end{aligned}
$$

where $R$ and $X$ are the resistance and inductance component of equivalent aggregated network impedance seen from the PCC to bus 1 in Fig. 1. Based on (15), the proposed strategy in (29) is rewritten as

$$
\begin{aligned}
& i_{m p \alpha}^{+*}=\left(k_{p} \frac{R}{\sqrt{R^{2}+X^{2}}}\right) \frac{2}{3} \frac{v_{\alpha}^{+}}{\left(v_{\alpha}^{+}\right)^{2}+\left(v_{\beta}^{+}\right)^{2}} P_{m}^{*}, \quad i_{m p \alpha}^{-*}=\left(1-k_{p} \frac{R}{\sqrt{R^{2}+X^{2}}}\right) \frac{2}{3} \frac{v_{\alpha}^{-}}{\left(v_{\alpha}^{-}\right)^{2}+\left(v_{\beta}^{-}\right)^{2}} P_{m}^{*} \\
& i_{m p \beta}^{+*}=\left(k_{p} \frac{R}{\sqrt{R^{2}+X^{2}}}\right) \frac{2}{3} \frac{v_{\beta}^{+}}{\left(v_{\alpha}^{+}\right)^{2}+\left(v_{\beta}^{+}\right)^{2}} P_{m}^{*}, \quad i_{m p \beta}^{-*}=\left(1-k_{p} \frac{R}{\sqrt{R^{2}+X^{2}}}\right) \frac{2}{3} \frac{v_{\beta}^{-}}{\left(v_{\alpha}^{-}\right)^{2}+\left(v_{\beta}^{-}\right)^{2}} P_{m}^{*} \\
& i_{m q \alpha}^{+*}=\left(k_{q} \frac{X}{\sqrt{R^{2}+X^{2}}}\right) \frac{2}{3} \frac{v_{\beta}^{+}}{\left(v_{\alpha}^{+}\right)^{2}+\left(v_{\beta}^{+}\right)^{2}} Q_{m}^{*}, \quad i_{m q \alpha}^{-*}=\left(1-k_{q} \frac{X}{\sqrt{R^{2}+X^{2}}}\right) \frac{2}{3} \frac{v_{\beta}^{-}}{\left(v_{\alpha}^{-}\right)^{2}+\left(v_{\beta}^{-}\right)^{2}} Q_{m}^{*} \\
& i_{m q \alpha}^{+*}=\left(k_{q} \frac{X}{\sqrt{R^{2}+X^{2}}}\right) \frac{2}{3} \frac{-v_{\alpha}^{+}}{\left(v_{\alpha}^{+}\right)^{2}+\left(v_{\beta}^{+}\right)^{2}} Q_{m}^{*}, \quad i_{m q \alpha}^{-*}=\left(1-k_{q} \frac{X}{\sqrt{R^{2}+X^{2}}}\right) \frac{2}{3} \frac{-v_{\alpha}^{-}}{\left(v_{\alpha}^{-}\right)^{2}+\left(v_{\beta}^{-}\right)^{2}} Q_{m}^{*}
\end{aligned}
$$

Based on (30), the maximum injected current under the unbalanced voltage sag is obtained as

$$
I_{\max m}^{*}=\max \left\{I_{m a}^{*}, I_{m b}^{*}, I_{m c}^{*}\right\}=\frac{2}{3} \sqrt{\left(I_{m}^{+^{*}}\right)^{2}+\left(I_{m}^{-*}\right)^{2}+2 I_{m}^{+^{* *} I_{m}^{-*} z}} .
$$

where

$$
\begin{aligned}
& I_{m}^{+*}=\sqrt{\left(I_{m p}^{+*}\right)^{2}+\left(I_{m q}^{+*}\right)^{2}}=\sqrt{\frac{\left(k_{p} \frac{R}{\sqrt{R^{2}+X^{2}}} P_{m}^{*}\right)^{2}+\left(k_{q} \frac{X}{\sqrt{R^{2}+X^{2}}} Q_{m}^{*}\right)^{2}}{\left(V^{+}\right)^{2}}} \\
& I_{m}^{-*}=\sqrt{\left(I_{m p}^{-*}\right)^{2}+\left(I_{m q}^{-*}\right)^{2}}=\sqrt{\frac{\left[\left(1-k_{p} \frac{R}{\sqrt{R^{2}+X^{2}}}\right) P_{m}^{*}\right]^{2}+\left[\left(1-k_{q} \frac{X}{\sqrt{R^{2}+X^{2}}}\right) Q_{m}^{*}\right]^{2}}{\left(V^{-}\right)^{2}}} \\
& z=\max \left\{\cos \left(\theta_{m}\right), \cos \left(\theta_{m}-\frac{2}{3} \pi\right), \cos \left(\theta_{m}+\frac{2}{3} \pi\right)\right\} \\
& \theta_{m}=\operatorname{atan} 2\left(I_{m q}^{+*}, I_{m p}^{+*}\right)+\operatorname{atan} 2\left(I_{m q}^{-*}, I_{m p}^{-*}\right)-\delta
\end{aligned}
$$

For the fourth equation in (31), $\delta$ that is defined as the sag angle between positive and negative sequences for deriving the maximum injected fault current, is expressed as [4], [13], [30]

$$
\begin{gathered}
\delta=\delta^{+}-\delta^{-}=\operatorname{atan} 2(\sin \delta, \cos \delta) . \\
\sin \delta=\frac{v_{\alpha}^{+} v_{\beta}^{-}+v_{\alpha}^{-} v_{\beta}^{+}}{V^{+} V^{-}}, \quad \cos \delta=\frac{v_{\alpha}^{+} v_{\alpha}^{-}-v_{\beta}^{+} v_{\beta}^{-}}{V^{+} V^{-}} .
\end{gathered}
$$

where $\operatorname{atan} 2$ is the two-argument arctangent function.

Based on (31), in order to avoid a sudden IBDG trip, the maximum injected current is limited to a security threshold. Thus, the PCL in ICG strategy is formulated as

$$
\begin{gathered}
{\left[\begin{array}{l}
i_{a}^{*} \\
i_{b}^{*} \\
i_{c}^{*}
\end{array}\right]=f(m) \times\left[\begin{array}{c}
i_{m p \alpha}^{+*}+i_{m p \alpha}^{-*}+i_{m q \alpha}^{+*}+i_{m q \alpha}^{-*} \\
-\frac{1}{2}\left(i_{m p \alpha}^{+*}+i_{m p \alpha}^{-*}+i_{m q \alpha}^{+*}+i_{m q \alpha}^{-*}\right)+\frac{\sqrt{3}}{2}\left(i_{m p \beta}^{+*}+i_{m p \beta}^{-*}+i_{m q \beta}^{+*}+i_{m q \beta}^{-*}\right) \\
-\frac{1}{2}\left(i_{m p \alpha}^{+*}+i_{m p \alpha}^{-*}+i_{m q \alpha}^{+*}+i_{m q \alpha}^{-*}\right)-\frac{\sqrt{3}}{2}\left(i_{m p \beta}^{+*}+i_{m p \beta}^{-*}+i_{m q \beta}^{+*}+i_{m q \beta}^{-*}\right)
\end{array}\right]} \\
f(m)= \begin{cases}1, & I_{\max m}^{*} \leq I_{\operatorname{limit} m} . \\
\frac{I_{\operatorname{limit} m}}{I_{\max m}^{*}}, & I_{\max m}^{*}>I_{\text {limit } m}\end{cases}
\end{gathered}
$$

For current inner loop control, the transfer function of proportional-resonant (PR) controller is described as [31]

$$
G(s)=\gamma_{P}+\gamma_{R} \frac{2 \omega_{c} s}{s^{2}+2 \omega_{c} s+\omega_{0}^{2}} .
$$

where $\omega_{0}$ is the resonant frequency and $\omega_{0}=100 \pi \mathrm{rad} / \mathrm{s}$.

\section{Design of Adjustable Coefficients}

\section{1) Design for FCM}

With considering PAS, the FCM coefficients are constrained

$$
I_{m}^{-}=\sqrt{\frac{\left[\left(1-k_{p} \frac{R}{\sqrt{R^{2}+X^{2}}}\right) P_{m}^{*}\right]^{2}+\left[\left(1-k_{q} \frac{X}{\sqrt{R^{2}+X^{2}}}\right) Q_{m}^{*}\right]^{2}}{\left(V^{-}\right)^{2}}}=\frac{I_{m q}^{-}}{\sin \left(\theta_{m w}^{-}\right)}
$$




$$
\tan \left(\theta_{m w}^{-}\right)=\frac{Q_{m}^{-}}{P_{m}^{-}}=\frac{\left(1-k_{q} \frac{X}{\sqrt{R^{2}+X^{2}}}\right) Q_{m}^{*}}{\left(1-k_{p} \frac{R}{\sqrt{R^{2}+X^{2}}}\right) P_{m}^{*}} .
$$

In practice, $k_{p}, k_{q}$ are designed using (37)-(38), as

$$
\begin{aligned}
& k_{p}=1+\frac{I_{m q}^{-}}{\sin \left(\theta_{m w}^{-}\right)} \frac{V^{-}}{P_{m}^{*} \sqrt{1+\left[\tan \left(\theta_{m w}^{-}\right)\right]^{2}}} \\
& k_{q}=1-\frac{I_{m q}^{-}}{\sin \left(\theta_{m w}^{-}\right)} \frac{V^{-}}{Q_{m}^{*} \sqrt{1+\frac{1}{\left[\tan \left(\theta_{m w}^{-}\right)\right]^{2}}}} .
\end{aligned}
$$

2) Design for active power oscillation elimination

In unbalanced voltage conditions, active power oscillations are hazardous due to ripples and harmonics. Using the proposed ICG strategy, the coefficients for the elimination of active power oscillation are designed as

$$
\begin{aligned}
& k_{p}=\frac{\sqrt{R^{2}+X^{2}}}{\left(1-\lambda^{2}\right) R} \\
& k_{q}=\frac{\sqrt{R^{2}+X^{2}}}{\left(1+\lambda^{2}\right) X}
\end{aligned}
$$

where $\lambda$ is the voltage unbalance factor, and $\lambda=V^{-} / V^{+}$.

\section{3) Design for reactive power oscillation elimination}

In unbalanced voltage conditions, reactive power oscillations should also be eliminated. Based on the proposed ICG strategy, the coefficients for the elimination of reactive power oscillation are designed as

$$
\begin{aligned}
& k_{p}=\frac{\sqrt{R^{2}+X^{2}}}{\left(1+\lambda^{2}\right) R} \\
& k_{q}=\frac{\sqrt{R^{2}+X^{2}}}{\left(1-\lambda^{2}\right) X}
\end{aligned}
$$

\section{E. Metric Indexes of FCM Strategy}

In this paper, one of main contributions is a more accurate PAS strategy to mitigate the IBDG fault current considering the SG effect. The PAS metric index is defined as the relative error of shifted phase angle, which is evaluated as

$$
R_{\text {angle }}=\frac{\theta_{m w}^{+/-*}-\theta_{m w}^{+/-}}{\theta_{m w}^{+l-*}} \times 100 \% .
$$

where $R_{\text {angle }}$ is the relative error of shifted phase angle, $\theta_{m w}^{+/-*}$ is the reference phase angle which can thoroughly mitigate the IBDG fault current.

Another main contribution is a more effective ICG strategy for voltage support considering the features of network impedance. The metric index of ICG is defined as relative error of supported positive sequence voltage amplitude or reduced negative sequence voltage amplitude, which is evaluated as

$$
R_{\mathrm{amp}}=\frac{V^{+/-*}-V^{+/-}}{V^{+/-*}} \times 100 \% .
$$

where $R_{a m p}$ is the relative error of positive/negative sequence voltage amplitude.

\section{F. FCM Strategy for MG Voltage Support}

The FCM strategy for MG voltage support with both IBDGs and SGs, which consists of PAS, PCS, and ICG, is illustrated in Fig. 4. The FCM and voltage support of MG are triggered and performed when a UG fault is detected and the PCC voltage sag is below $90 \%$.

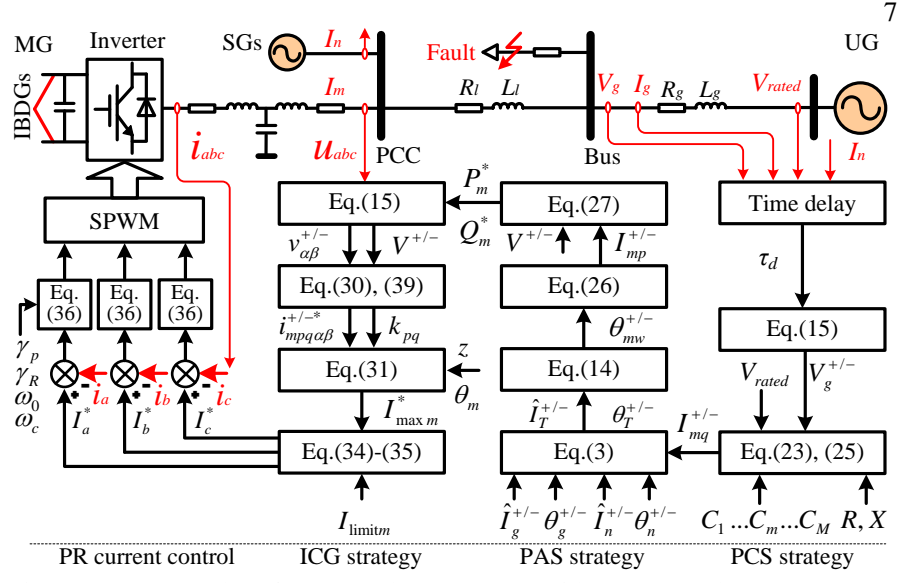

Fig. 4. FCM procedure for MG voltage support with IBDGs and SGs.

The time delays are analyzed as follows: The FCM strategy requires the related fault and operation data from both UG and MG. In practice, the impact of time delays $\left(\tau_{d}\right)$, which are caused by the use of measurement devices, communication links for data transmission, and controller process time, are of great concern for the performance of FCM strategy. In terms of measurement delay, sensors and phasor measurement units (PMUs) are used to measure real-time operation data, such as voltage, current, angle.

Once fault occurs, there will be measurement delays, which represent sensor and process delays for converting sensor data to phasor/digital signals [32]. In general, the total measurement delay in power system control is reported to be in the order of milliseconds [32]. In terms of communication delays, the real-time measured UG fault voltage and current signals are transmitted to MG local control center using the advanced communication infrastructure and through long distance communication links [33]-[34]. The communication time delays are varied by the number of signals, channel bandwidths, communication distances and types of communication links which are mainly divided into wireless (e.g., microwave and satellites) and wired (e.g., fiber optic cables, telephone lines) [33]. The time delays in fiber optic digital communication is around $38 \mathrm{~ms}$ for one way, while the delay using modems via microwave is over $80 \mathrm{~ms}$ [34].

In addition, the control performance would not be generally affected when the time delay is less than $10 \mathrm{~ms}$ [34]. The total communication delay in power system control is often considered to be 100-700 ms [32], and about $150-300 \mathrm{~ms}$ for fiber optic and microwave [34]. In terms of process delays, the response of digital terminal device itself (sender and receiver), such as PMUs, phasor data concentrators (PDCs) and inverter controller, will generate process delays [35]. In practice, terminal process delays can be limited to small ranges or even fixed to constants [35]. It is important to highlight that unlike power electronic control delays which are in microseconds, the process delays are in the order of milliseconds [35]. In this paper, for the sake of analyses, we are not considering measurement, communication, and process delays separately. Assuming that the fault data are transmitted via the same communication lines, the time delay $\left(\tau_{d}\right)$ is tested as $0 \mathrm{~ms}, 60 \mathrm{~ms}$ and $150 \mathrm{~ms}$ in order to estimate its impact on FCM strategy [32]-[35].

The differences in FCM strategy when MG is operating in islanding or UG-connected are summarized as follows: 1) When the fault occurs at UG and MG is transferred to island operation, the MG voltage is controlled by inverter and the FCM strategy is unnecessary for fault current management; 2) When the fault 
occurs at $\mathrm{UG}$ and $\mathrm{MG}$ is still at UG-connected operation, the MG voltage follows the UG voltage, and the FCM strategy is necessary to avoid high-level total fault current during MG voltage support; 3) When the fault occurs at islanded MG, MG becomes an independent system. Accordingly, the FCM strategy is needed when MG is large and may not be needed when MG is small.

The differences in FCM strategy between disturbances/fault and steady state conditions are summarized as follows: 1) In a fault condition, it is necessary to support PCC voltage sags. The proposed FCM strategy is significant for fault current management during voltage support; 2) At steady state, FCM and voltage support of MG are unnecessary since the voltage will quickly return to normal.

The actual hardware requirements for the realization of FCM are summarized as follows: 1) Sensors are needed to detect the SG output voltage and currents, amplitude and phase angle of UG fault current, and amplitude and phase angle of fault current at fault branch; 2) Corresponding communication lines are needed for the transmission of fault current data; 3) Inverter needs more input/output (I/O) interface to receive the fault data; 4) In order to mitigate IBDG fault currents, the PAS module is necessary in inverter to calculate the phase angle of output fault current; 5) The PCS calculation module is necessary in inverter to match the PAS function with the coordinated operations of IBDGs and SGs.

The implementation of the FCM strategy is analyzed as follows: 1) It is easy to implement the FCM strategy in inverter products since only PAS and PCS strategies need to be added before the power calculation. First, reactive current is calculated for voltage support. Second, phase angle is calculated based on PAS strategy. Third, active current is calculated based on the determined phase angle. Fourth, active/reactive power is calculated based on the PCS strategy; 2) The FCM strategy can be implemented in different inverter products such as power convert system, photovoltaic inverter, back to back converter, and HVDC transmission system for AC-DC-DC-AC. The fault current impact injected by these products can be mitigated.

\section{CASE STUdY}

\section{A. System Data}

In order to demonstrate the effectiveness of the proposed FCM strategy, an UG-connected MG which consists of two parallel IBDGs and two parallel SGs is conducted based on Matlab/Simulink. The performance is tested and analyzed using a 0.3 p.u. three-phase unbalanced voltage sag. The network and control parameters are given in Tables II and III, respectively.

\section{B. PCL Analyses in ICG Strategy}

In order to verify the effectiveness of the ICG strategy during the MG voltage support, the PCC phase voltage is tested in a fault condition as shown in Fig. 5. The normal phase voltage amplitude is $311 \mathrm{~V}$. The fault occurs at $0.05 \mathrm{~s}$ and is cleared at $0.35 \mathrm{~s}$. In order to validate the effectiveness of the proposed strategy in extreme voltage changes, the fault voltage is designed to have step changes. The $k_{p}$ and $k_{q}$ in the proposed ICG strategy are set so that cases with and without PCL have the same trend as shown in Fig. 6 [3]-[4]. The coefficients are applied to eliminate reactive power oscillations at $\mathrm{t}=0.05-0.10 \mathrm{~s}$ and eliminate active power oscillations at $\mathrm{t}=0.30-0.35 \mathrm{~s}$. In addition, during $\mathrm{t}=0.10-0.30 \mathrm{~s}$, the coefficients are applied to continuously alter from the reactive power oscillation elimination to the active power oscillation elimination; the coefficient change can also demonstrate the flexible adjustment of power/current.

TABLE II

NETWORK PARAMETERS

\begin{tabular}{cccc}
\hline Parameters & Symbol & Value & Unit \\
\hline Network impedance between UG and fault bus & $R_{g} / L_{g}$ & $0.2 / 1.18$ & $\Omega / \mathrm{mH}$ \\
Network impedance between MG and fault bus & $R_{l} / L_{l}$ & $1.5 / 1$ & $\Omega / \mathrm{mH}$ \\
DC capacitor & $C_{d c}$ & 40 & $\mu \mathrm{F}$ \\
Inverter side impedance of LCL filter & $R / L$ & $0.01 / 2.5$ & $\Omega / \mathrm{mH}$ \\
Utility grid side impedance of LCL filter & $R / L$ & $0.01 / 0.5$ & $\Omega / \mathrm{mH}$ \\
Capacitor of LCL filter & $C_{\text {filter }}$ & 40 & $\mu \mathrm{F}$ \\
Grid nominal voltage & $V_{\text {rated }}$ & 311 & $\mathrm{~V}$ \\
DC voltage & $u_{d c}$ & 800 & $\mathrm{~V}$ \\
Grid nominal frequency & $f$ & 50 & $\mathrm{~Hz}$ \\
Cutoff angular frequency & $\omega_{c}$ & 70 & $\mathrm{rad} / \mathrm{s}$ \\
Switching frequency & $f_{s}$ & 10 & $\mathrm{kHz}$ \\
Nameplate capacity of IBDG \#1 & $C_{l}$ & 14 & $\mathrm{~kW}$ \\
Nameplate capacity of IBDG \#2 & $C_{2}$ & 6 & $\mathrm{~kW}$ \\
Nameplate capacity of SG \#1 & $C N_{l}$ & 2 & $\mathrm{~kW}$ \\
Nameplate capacity of SG \#2 & $C_{2}$ & 5 & $\mathrm{~kW}$ \\
\hline
\end{tabular}

TABLE III

CONTROL PARAMETERS

\begin{tabular}{ccc}
\hline Parameters & Symbol & Value \\
\hline Adjustable coefficients of IBDG \#1 without FCM & $\mathrm{kp} / \mathrm{kq}$ & $1.015 / 0.984$ \\
Adjustable coefficients of IBDG \#2 without FCM & $\mathrm{kp} / \mathrm{kq}$ & $1.006 / 0.969$ \\
Adjustable coefficients of IBDG \#1 with FCM & $\mathrm{kp} / \mathrm{kq}$ & $1.011 / 0.974$ \\
Adjustable coefficients of IBDG \#2 with FCM & $\mathrm{kp} / \mathrm{kq}$ & $1.002 / 0.965$ \\
PR controller with/without FCM & $\gamma p, \gamma_{R}$ & 500,4500 \\
\hline
\end{tabular}

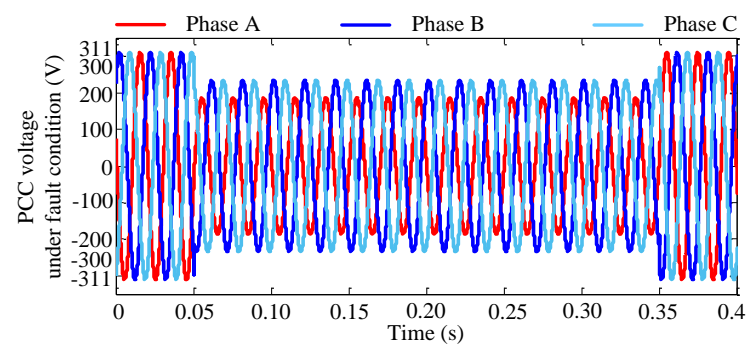

Fig. 5. PCC voltage in fault condition.

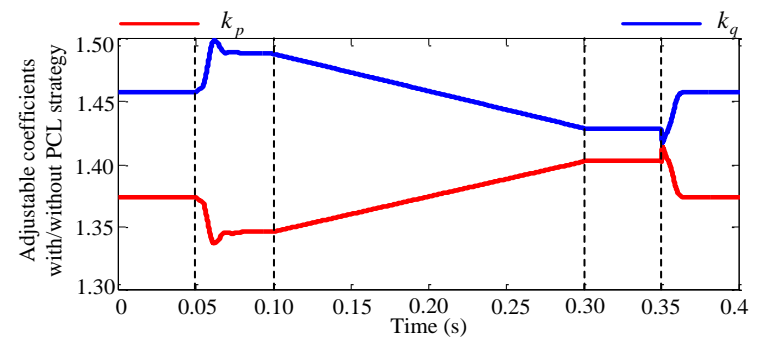

Fig. 6. Adjustment coefficients by ICG with and without PCL in [3]-[4].

Since fault voltage sags in phases $\mathrm{b}$ and $\mathrm{c}$ are the same in Fig. 5 , the comparison of IBDG injected current without/with PCL is tested in phases a and $b$, as shown in Fig. 7. Assuming the prescribed safety threshold of inverter is $40 \mathrm{~A}$, when the pre-fault injected current is $40 \mathrm{~A}$, the injected current during fault tends to exceed threshold without PCL [3]-[4], which could trip IBDGs. However, the injected current is consistently below its threshold with PCL. After fault is cleared, the injected current would return to be normal.

Based on Figs. 5 and 6, the comparison of IBDG injected active and reactive power without/with PCL is shown in Fig. 8. At the pre-fault condition, the PCC voltage is normal and the IBDG active and reactive power remain unchanged. At the post-fault condition, the functions of reactive power oscillation elimination, flexible power regulation, and active power oscillation elimination are effectively tested and verified. In the existing method without PCL [3]-[4], active and reactive power delivery are maintained the same as those before fault. 
Correspondingly, the fault current amplitude reaches 63A (in Fig. 7), which exceeds the $40 \mathrm{~A}$ threshold. In the proposed method with PCL, active and reactive power are lower than without PCL in [3]-[4]. Thus, the maximum fault current amplitude is effectively controlled to fall below threshold. After fault, the delivered amounts of active and reactive power return to their pre-fault conditions.

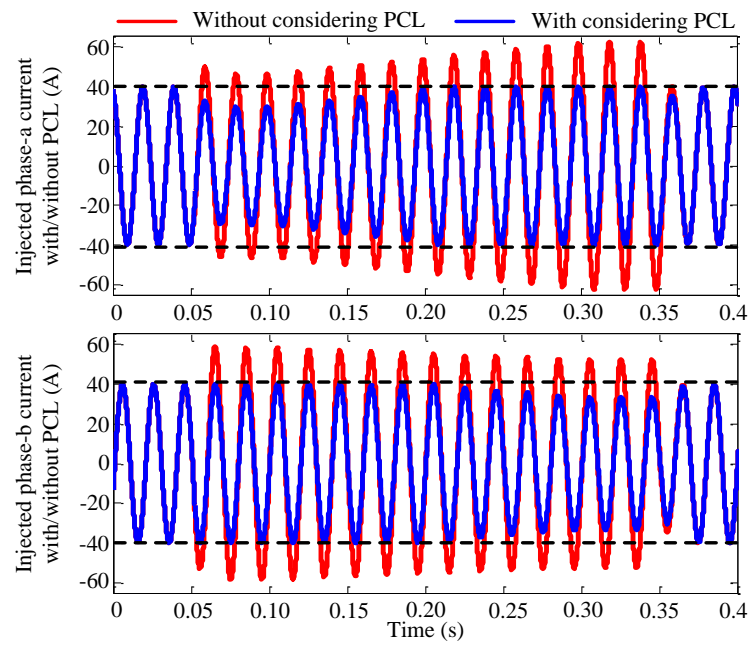

Fig. 7. Injected current by ICG with and without PCL in [3]-[4].

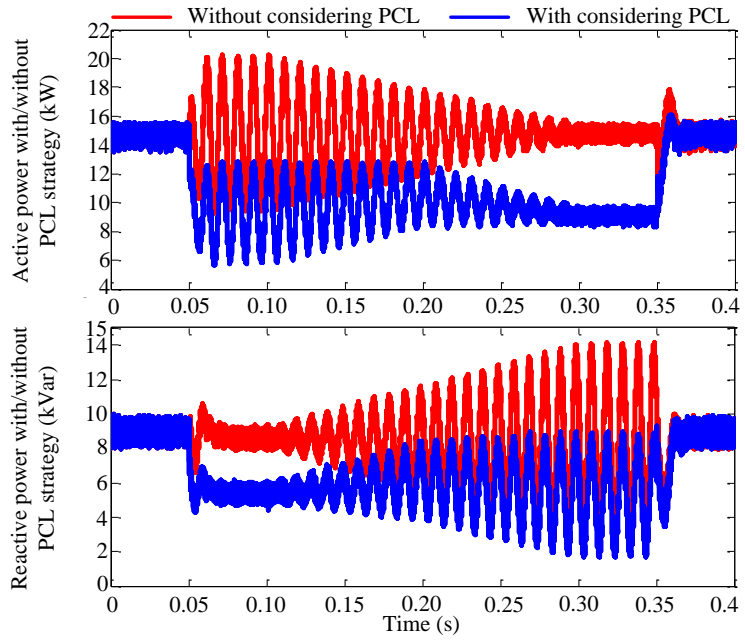

Fig. 8. Injected power by ICG with PCL and without PCL in [3]-[4].

\section{Adjustment Coefficients Analyses in ICG strategy}

In order to highlight the effectiveness of proposed ICG strategy in (30), the adjustable coefficients are tested as shown in Fig. 9. Using the same trend for $k_{p}$ and $k_{q}$, it is clear that the proposed strategy is more effective than the existing strategy in [9],[13]-[14] for both positive sequence voltage amplitude recovery and the negative sequence voltage amplitude reduction. Thus, this strategy can further enhance the MG voltage support capability in fault conditions.

Based on Fig. 9, the metric index comparison between proposed and existing ICG strategies is shown in Fig. 10. Compared to the existing strategy [9], [13]-[14], the proposed ICG strategy is more effective for voltage support since it has a smaller relative error in both supported positive sequence voltage and reduced negative sequence voltage. It is worth noting that the existing ICG strategy can also ensure that the relative error is less than $10 \%$ by regulating the adjustable coefficients during voltage support.
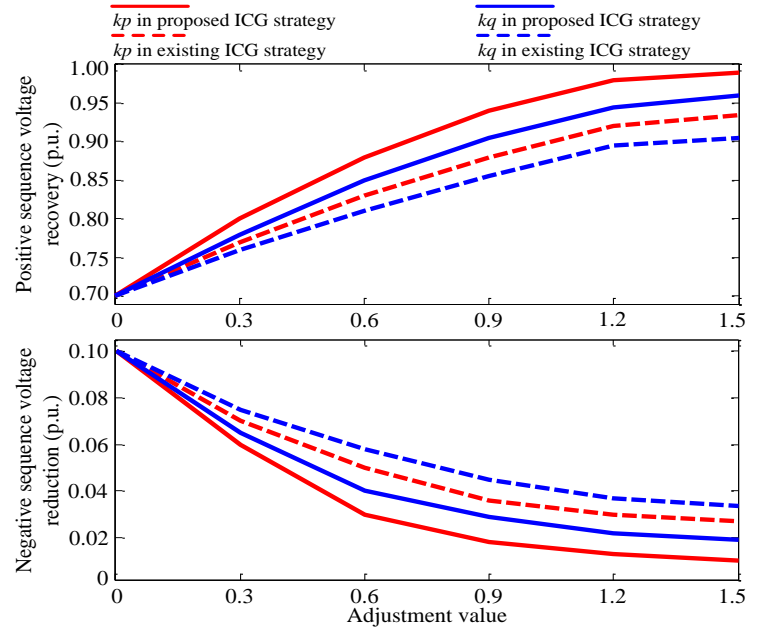

Fig. 9. Comparison between the proposed and the existing ICG strategy in [9], [13]-[14].

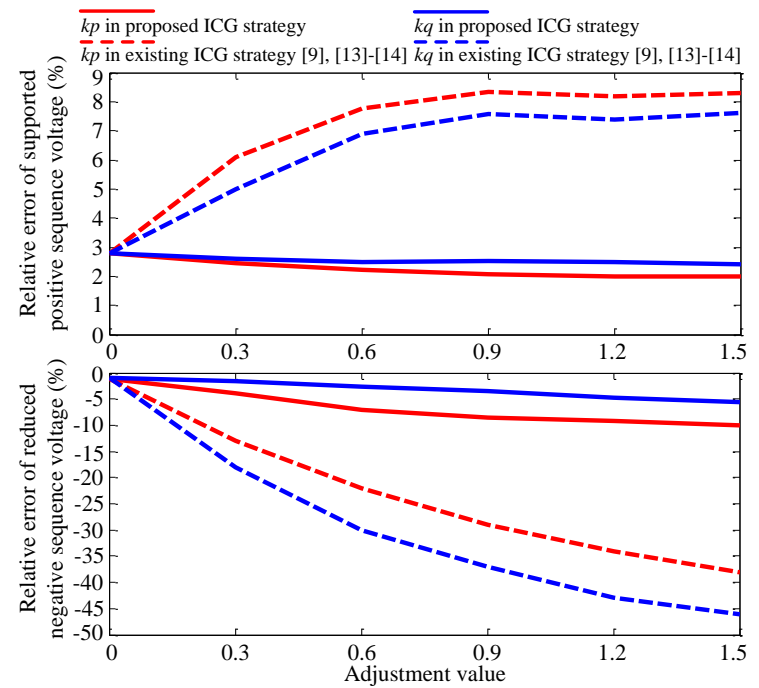

Fig. 10. Metric index comparison between the proposed and the existing ICG strategy in [9], [13]-[14].

\section{PAS Strategy}

Taking the positive sequences phase angle as an example, Fig. 11 shows the fault current phase angle for different PAS strategies. In the case without the PAS strategy in [3]-[4], the phase angle of the IBDG fault current is almost the same regardless of IBDG nameplate capacity, since they have the same angle relative to PCC voltage. In the cases with the proposed and the existing PAS, the fault current phase angle is different since the amplitude and phase angel of controllable and uncontrollable fault currents are different. When the phase angle calculated by PAS strategy is different, the shifted phase angle of IBDG fault current would also be different. For a different IBDG, the larger the capacity, the larger the fault current is; so, the shifted phase angle is larger. For the same IBDG, in the case with proposed PAS when SG is considered, the fault current phase angle is larger than that of the existing PAS strategy given in [9]. The proposed PAS strategy can mitigate the impact of MG fault current effectively because of a more precise shifted phase angle (see Section IV.E).

Based on Fig. 11, the metric index comparison of shifted phase angle with different PAS strategies is shown in Fig. 12. In the case without the PAS strategy, the relative error of the shifted phase angle is much larger since the phase angle is not adjusted. The reason the relative errors in IBDG\#1 and IBDG\#2 are different is that the reference phase angle is related to the 
nameplate capacity. Compared to the existing PAS strategy [9], the proposed PAS strategy is more accurate since its relative error is much smaller, and is close to zero, regardless of IBDG nameplate capacity. Therefore, the proposed PAS strategy can mitigate the impact of IBDG fault current more thoroughly than existing PAS strategy [9] (see Section IV.E).

Considering a symmetrical fault as an example, in order to validate the effective of proposed FCM strategy under different operation scenarios, the system is tested with several voltage

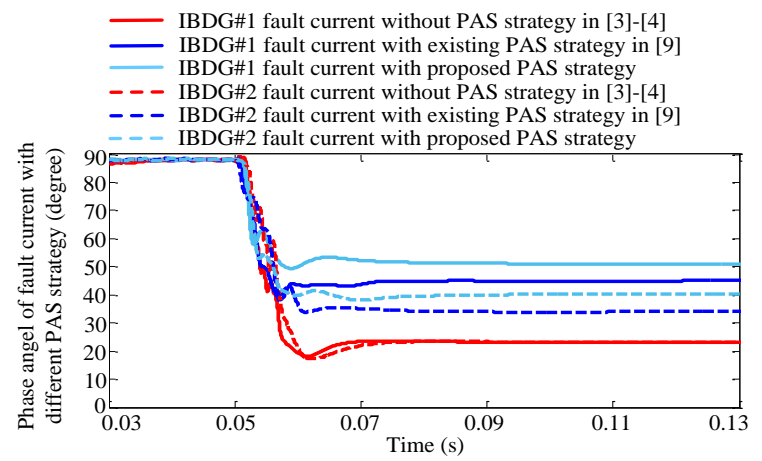

Fig. 11. Phase angle of fault current with different PAS strategies.

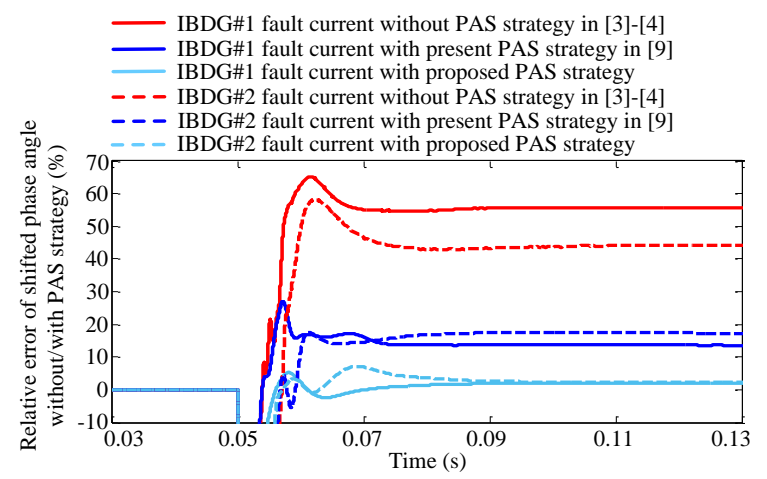

Fig. 12. Comparison of shifted phase angle with different PAS strategies. sags (ranging from 10\%-0100\%), network impedances, and short circuit ratios (SCRs) [33], [36]. The PCC voltage for different fault sag depths is shown in Fig. 16. Taking IBDG\#1 as an example, the fault current for different fault sag depths is shown in Fig. 17. Here, the larger the voltage sag, the larger the fault current is. The fault current with the FCM strategy is larger than that without the FCM strategy. The fault current with the proposed FCM strategy is larger than that with the existing FCM strategy since the proposed PAS has a more precise shifted phase angle and needs larger fault current for voltage support as verified in Fig. 13.

\section{E. FCM Strategy}

In order to verify the effectiveness of the FCM strategy during MG voltage support, the injected IBDG fault current is listed for three phases in Fig. 13. Based on Fig. 5, the fault occurs at 0.05s. When fault occurs, the fault current is injected which is shared by PCS strategy based on the IBDG nameplate capacity. The maximum fault current is below the $40 \mathrm{~A}$ prescribed safety threshold by PCL strategy.

For the fault current phase angle, the shifted phase angel with the proposed PAS strategy is larger than that with the existing PAS strategy. By comparing fault currents in IBDG\#1 and IBDG\#2, we learn that the larger the fault current, the larger shifted phase angle is during fault. For the amplitude of fault current, the more the phase angle is shifted, the larger the amplitude of fault current would be for the purpose of voltage support during fault. The total fault currents in three phases are listed in Fig. 14 for different FCM strategies. The total fault current includes UG, SG, and IBDG fault currents, and the uncontrollable fault current includes UG and SG fault currents.
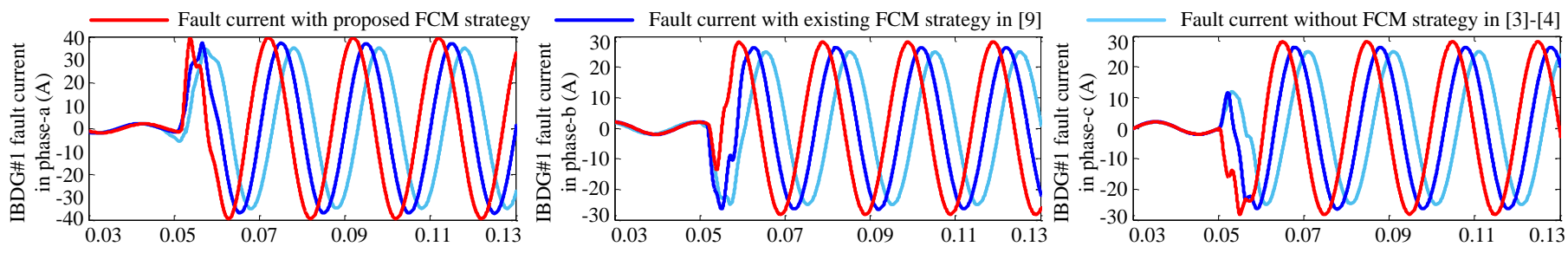

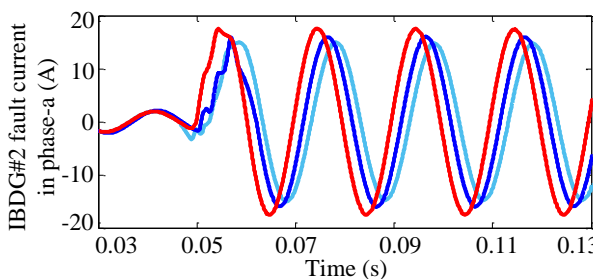

(a)

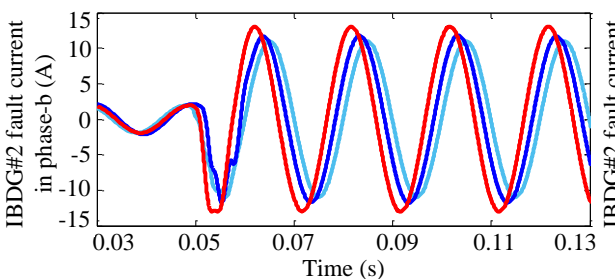

(b)

Fig. 13. Fault current injected by IBDG\#1 and IBDG\#2: (a) in phase a; (b) in phase b; (c) in phase $c$

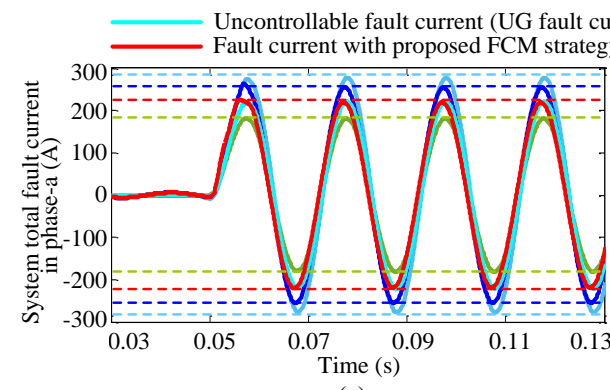

(a)

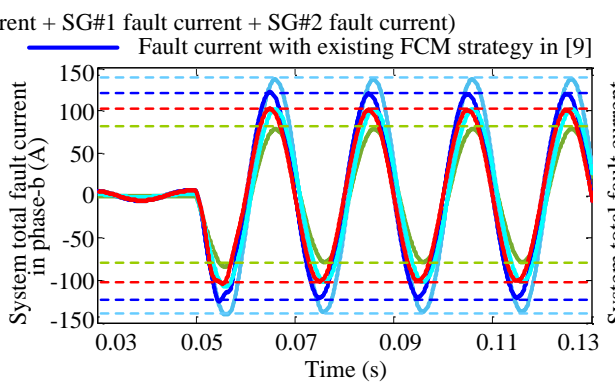

(b)

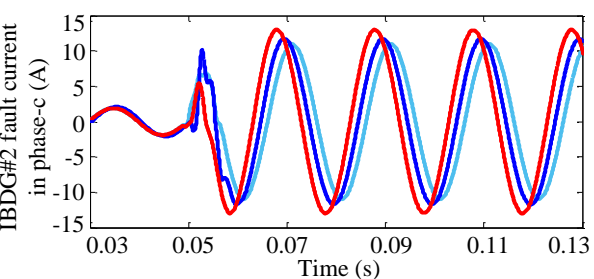

(c)

Fig. 14. System total fault current with different FCM strategy: (a) in phase a; (b) in phase b; (c) in phase c.

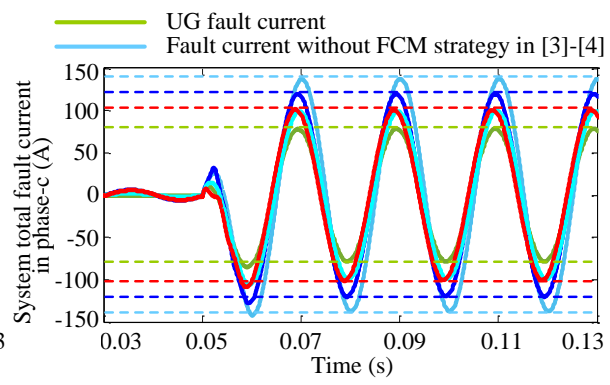

(c) 


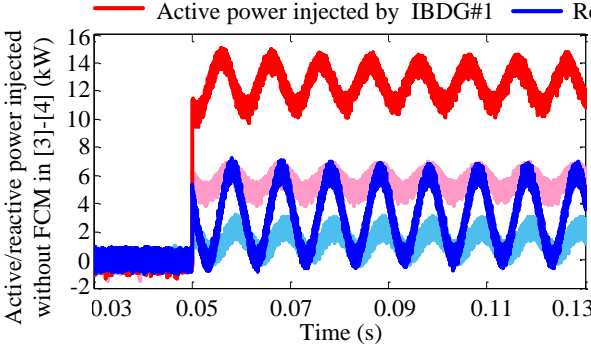

(a)

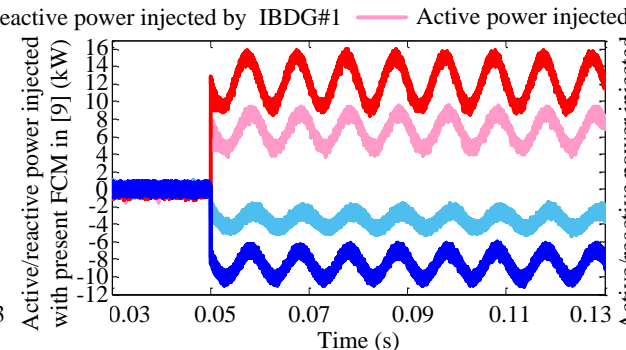

(b)

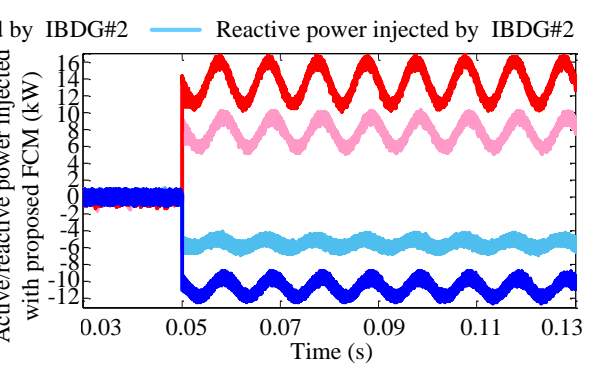

(c)

Fig. 15. Active/reactive power injected with different FCM strategy: (a) without FCM in [3]-[4]; (b) with existing FCM in [9]; (c) with proposed FCM.

Here, the total fault current without the PAS strategy [3]-[4] is much larger than the uncontrollable fault current. The total fault current with the existing PAS strategy [9] is larger than the uncontrollable fault current. While, the total fault current with the proposed PAS strategy is almost the same as that of the uncontrollable fault current. For example, the uncontrollable fault current in phase- $a$ is $219 \mathrm{~A}$, while the total fault currents without the PAS strategy [3]-[4], with the existing PAS strategy [9], and with the proposed PAS strategy are 283A, 255A, 220A, respectively.

Based on the proposed FCM strategy, the IBDG fault current is almost mitigated. Therefore, the MG fault current has the minimum impact on the amplitude of total fault currents during the MG voltage support which includes both IBDGs and SGs. The active and reactive power injected with different FCM strategies are shown in Fig. 15. Due to the shifted current phase angle by the PAS strategy, the amount and the angle of active and reactive power are different during the MG voltage support without the FCM strategy given in [3]-[4], with the existing FCM strategy given in [9] and with the proposed FCM strategy.

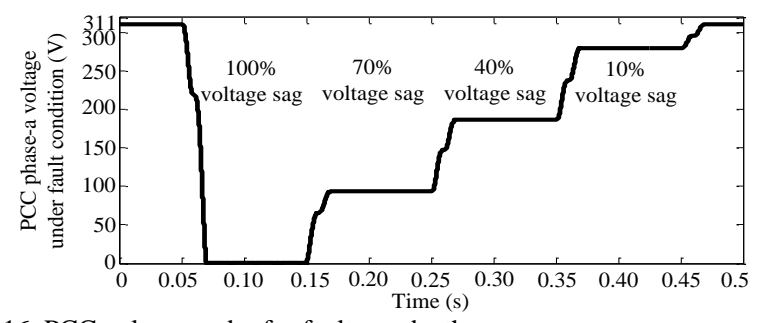

Fig. 16. PCC voltage under for fault sag depths.

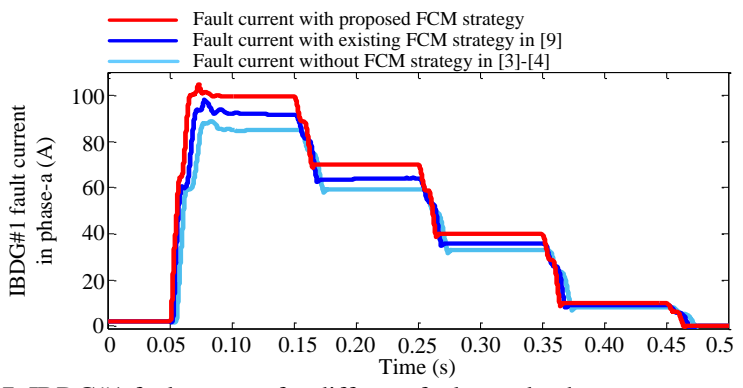

Fig. 17. IBDG\#1 fault current for different fault sag depths.

\section{F. Multiple Operation Scenario Analyses}

Taking the $60 \%$ voltage sag as an example, the IBDG\#1 fault current for different network impedances is shown in Fig. 18. In Fig. $18(\mathrm{a}), L_{l}=1 \mathrm{mH}$ while $R_{l}$ is $1.5 \Omega, 2.0 \Omega, 2.5 \Omega$ at $\mathrm{t}=1.0-1.1 \mathrm{~s}, \mathrm{t}=1.1-1.2 \mathrm{~s}, \mathrm{t}=1.2-1.3 \mathrm{~s}$, respectively. In Fig. 18(b), $R_{l}=1.5 \Omega$ while $L_{l}$ is $1 \mathrm{mH}, 1.5 \mathrm{mH}, 2.0 \mathrm{mH}$ at $\mathrm{t}=1.0-1.1 \mathrm{~s}$, $\mathrm{t}=1.1-1.2 \mathrm{~s}, \mathrm{t}=1.2-1.3 \mathrm{~s}$, respectively. As can be seen, the larger the network impedance, the smaller the fault current is. The dynamic response and steady state amplitude size of fault current vary with network impedance and FCM strategy. The amplitude relationship of fault current in the proposed FCM, existing FCM and without FCM strategy can also be verified in Figs. 13 and 17. Taking the $60 \%$ voltage sag as an example, IBDG\#1 fault current for different SCRs is shown in Fig. 19. The SCRs are 4.0, 4.7, 5.6 at $\mathrm{t}=1.0-1.1 \mathrm{~s}, \mathrm{t}=1.1-1.2 \mathrm{~s}, \mathrm{t}=1.2-1.3 \mathrm{~s}$, respectively. When the equipment capacity is fixed, a larger SCR corresponds with a larger system capacity, a smaller system equivalent impedance, and a larger fault current for voltage support.

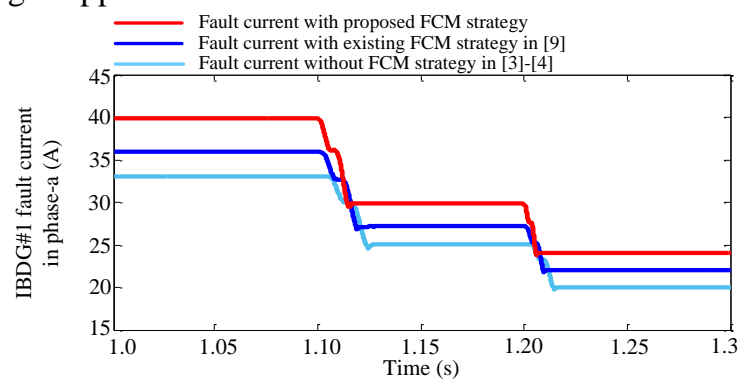

(a)

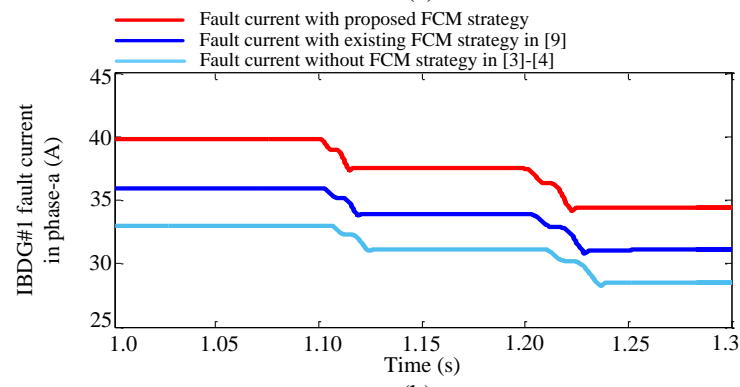

(b)

Fig. 18. IBDG\#1 fault current for different network impedances.

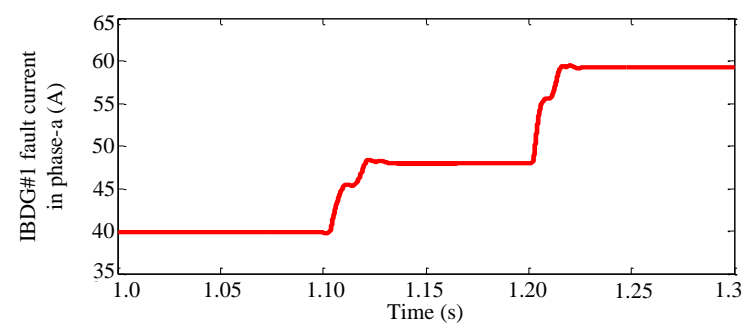

Fig. 19. IBDG\#1 fault current for different SCRs.

\section{G. Time Delay Analyses}

Taking the phase- $a$ current as an example, Fig. 20 shows the impact of time delay on the amplitude of total fault current. In case there is no time delay, the FCM strategy can be operated immediately. Otherwise, the FCM strategy would be delayed since the phase angle of IBDG fault current is updated and 
shifted once the fault current data is received. Compared to the existing FCM strategy in [9], the proposed FCM strategy has a better mitigation capability, since the total fault current amplitude is almost equal to the uncontrollable fault current.

The length of time delay does not affect the nature of the FCM strategy. In practice, the FCM can be activated and realized once the time delay ends. Considering that the voltage support can be executed by the MG local control when the PCC fault voltage sags below $90 \%$, with a minute communication delay, the voltage support can be first conducted by a traditional method. Then, when the remote UG fault current data are transferred to the MG local controller, the FCM strategy can be activated to mitigate the IBDG fault current. In this way, the voltage support and FCM will not be affect by time delays, even when there is a few second time delay.

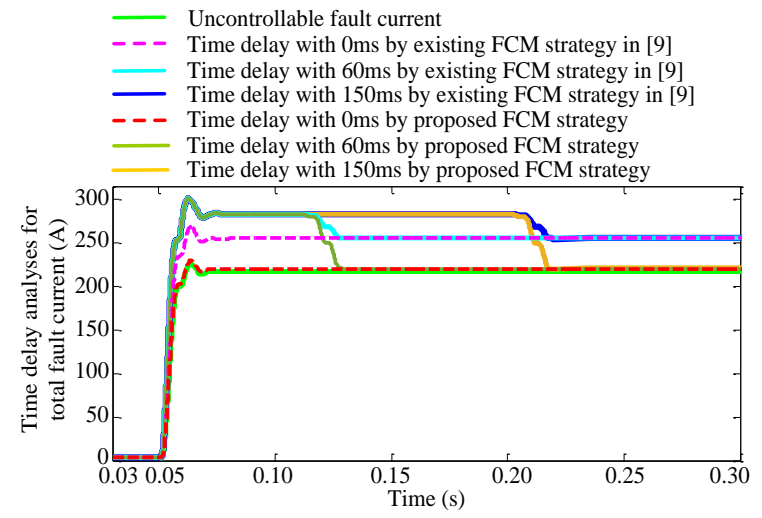

Fig. 20. Time delay analyses.

\section{H. Protection Operation Analyses}

The penetration of MGs will increase the total fault current, which can cause protection system failures. The proposed FCM strategy mitigates the IBDG fault current and contributes the minimum MG fault current to the total fault current amplitude. However, once relay protection devices are designed and deployed, the protection system operation (e.g., over-current amplitude protection and coordination between primary and secondary protective devices) may be disturbed if the fault current is decreased [37]. In this paper, we assume relay protection devices are designed based on a traditional power distribution network (PDN) without MGs. However, once MGs are deployed, the total fault current amplitude during the MG voltage support will increase in the ascending order of without MG, with MG and FCM, and with MG and without FCM. The FCM strategy cannot decrease the total fault current below that of traditional PDN without MG. Therefore, once the fault occurs, the relay protection uses the FCM strategy to operate the same as that in a traditional PDN, even when MGs are integrated later. In this paper, we emphasize that the relay protection is applied to the over-current amplitude protection.

\section{Other Analyses}

Compared with the existing protection solutions, the proposed strategy provides the following improvements:

1) Field applications are more practical: compared with the results presented in [3], [9], [13]-[18], the proposed approach offers more practical FCM and voltage support strategies since SG effects in MGs are considered.
2) Fault current is mitigated more thoroughly: (i) compared with the peak current limiting method stated in [13]-[14], the amplitude of IBDG fault current in this paper is limited to safety peaks to protect the inverter; also, the impact of IBDG fault current on the total fault current can only be reduced rather than mitigated; (ii) compared with that in [9], the shifted phase angle of IBDG fault current is more precise in this paper; thus the impact of IBDG fault current on the total fault current is further mitigated.

3) Protective equipment dependence is reduced: compared with those in [8]-[9], the fault current protection will not be overly dependent on installing extra protection equipment, such as FCL [8], since the impact of IBDG fault current is negligible.

4) Relay protection dependence is reduced: compared with those in [5]-[6], the application of FCM strategy is beneficial to relay protection equipment considering the impact of fault current increment.

5) Voltage support performance is better: (i) compared with that in [3], the nameplate capacity/local IBDG current is considered for the coordinated operation of parallel DGs located inside MG; (ii) compared with those in [13]-[14], the network impedances are considered to achieve a better voltage support performance.

6) Time delay is considered: compared with that in [9], the fault time delay is analyzed for the fault current management.

\section{V.CONCLUSION}

Considering different fault current characteristics injected by SGs and IBDGs during the MG voltage support, the proposed FCM strategy for IBDGs will minimize the impact of MG fault current on the amplitude of total fault current. The PAS strategy is proposed in order to enhance the mitigation effect of the FCM strategy, which offers a more precise phase angle shifting with comprehensive considerations of IBDG, SG and UG fault currents. In order to match the PAS function, the PCS strategy is developed for the coordinated operation of DGs with SGs. In order to provide a better voltage support performance, an ICG strategy is formulated by combining the features offered by injected current and network impedance. Using the ICG strategy, PCL is developed for a safe operation. Several tests have validated the effectiveness of the proposed FCM strategy with MG fault current, which uses IBDGs and SGs to offer the minimum impact on the amplitude of total fault current during the MG voltage support.

\section{REFERENCES}

[1] C. Li, X. Liu, W. Zhang, Y. Cao, X. Dong, F. Wang and L. Li, "Assessment Method and Indexes of Operating States Classification for Distribution System With Distributed Generations," IEEE Trans. Smart Grid, vol. 7, no. 1, pp. 481-490, Jan. 2016.

[2] A. Camacho, M. Castilla, J. Miret, R. Guzman and A. Borrell, "Reactive Power Control for Distributed Generation Power Plants to Comply With Voltage Limits During Grid Faults," IEEE Trans. Power Electron., vol. 29, no. 11, pp. 6224-6234, Nov. 2014.

[3] X. Zhao, J. M. Guerrero, M. Savaghebi, J. C. Vasquez, X. Wu and K. Sun, "Low-Voltage Ride-Through Operation of Power Converters in Grid-Interactive Microgrids by Using Negative-Sequence Droop Control," IEEE Trans. Power Electron., vol. 32, no. 4, pp. 3128-3142, April 2017.

[4] A. Camacho, M. Castilla, J. Miret, L. Vicuna and R. Guzman, "Positive and Negative Sequence Control Strategies to Maximize the Voltage 
Support in Resistive-Inductive Grids During Grid Faults," IEEE Trans. Power Electron., vol. 33, no. 6, pp. 5362-5373, June 2018.

[5] A. Beheshti, M. Shanbedi, S. Z. Heris, "Heat transfer and rheological properties of transformer oil-oxidized MWCNT nanofluid," Journal of Thermal Analysis and Calorimetry, vol. 118, no. 3, pp. 1451-1460, Dec. 2014.

[6] L. Che, M. Khodayar, and M. Shahidehpour, "Adaptive protection system for microgrids: Protection practices of a functional microgrid system," IEEE Electrification Magazine, vol. 2, no. 1, pp. 66-80, Mar. 2014

[7] I. Sadeghkhani, M. E. H. Golshan, J. M. Guerrero, A. M. Sani, “A Current Limiting Strategy to Improve Fault Ride-Through of Inverter Interfaced Autonomous Microgrids," IEEE Trans. Smart Grid, vol. 8, no. 5, pp. 2138-2148, Sep. 2017.

[8] H. Nourmohamadi, M. Sabahi, E. Babaei, M. Abapour, "A New Structure of Fault Current Limiter Based on the System Impedance with Fast Eliminating Method and Simple Control Procedure," IEEE Trans. on Industrial Electronics, vol. 65, no. 1, pp. 261-269, Jan. 2018.

[9] W. Kou and D. Wei, "Fault ride through strategy of inverter-interfaced microgrids embedded in distributed network considering fault current management," Sustainable Energy, Grids and Networks, vol. 15, pp. 43-52, 2018.

[10] IEEE Standard for Interconnecting Distributed Resources With Electric Power Systems, IEEE Standard 1547, 2003.

[11] S. Chaitusaney and A. Yokoyama, "Prevention of reliability degradation from recloser-fuse miscoordination due to distributed generation," IEEE Trans. Power Del., vol. 23, no. 4, pp. 2545-2554, Oct. 2008.

[12] X. Liu, C. Li, M. Shahidehpour, Y. Gao, B. Zhou, et al, "Fault Current Hierarchical Limitation Strategy for Fault Ride-Through Scheme of Microgrid," IEEE Trans. Smart Grid, vol. 10, no. 6, pp. 6566-6579, 2019.

[13] M. M. Shabestary, Y. A. I. Mohamed, "Analytical Expressions for Multiobjective Optimization of Converter-Based DG Operation Under Unbalanced Grid Conditions," IEEE Trans. Power Electron., vol. 32, no. 9, pp. 7284-7296, Sept 2017.

[14] S. Teimourzadeh, F. Aminifar, M. Davarpanah, and M. Shahidehpour, "Adaptive protection for preserving microgrid security," IEEE Trans. Smart Grid, vol. 10, no. 1, pp. 592-600, Jan. 2019

[15] N. Jelani and M. Molinas, "Asymmetrical fault ride through as ancillary service by constant power loads in grid-connected wind farm," IEEE Trans. Power Electron., vol. 30, no. 3, pp. 1704-1713, Mar. 2015.

[16] A. Camacho, M. Castilla, J. Miret, J. C. Vasquez, and E. Alarcon-Gallo, "Flexible voltage support control for three-phase distributed generation inverters under grid fault," IEEE Trans. Ind. Electron., vol. 60, no. 4, pp. 1429-1441, Apr. 2013

[17] N. Rajaei, M. H. Ahmed, M. M. A. Salama and R. K. Varma, "Fault Current Management Using Inverter-Based Distributed Generators in Smart Grids," IEEE Trans. Smart Grid, vol. 5, no. 5, pp. 2183-2193, Sept. 2014.

[18] Y. Yang, F. Blaabjerg, and Z. Zou, "Benchmarking of grid fault modes in single-phase grid-connected photovoltaic systems," IEEE Trans. Ind. Appl., vol. 49, no. 5, pp. 2167-2176, Sep./Oct. 2013.

[19] M. Castilla, et al. "Voltage support control strategies for static synchronous compensators under unbalanced voltage sags," IEEE Trans. Ind. Electron., vol. 61, no. 2, pp. 808-820, Feb. 2014.

[20] S. Mortazavian; M. M. Shabestary; Y. Abdel-Rady I. Mohamed, "Analysis and Dynamic Performance Improvement of Grid-Connected Voltage-Source Converters under Unbalanced Network Conditions," IEEE Trans. Power Electron., vol. 32, no.10, pp. 8134-8149, Oct. 2017

[21] A. Moawwad, et al. "Advanced Fault Ride-Through Management Scheme for VSC-HVDC Connecting Offshore Wind Farms," IEEE Transactions on Power Systems, vol. 31, no. 6, pp. 4923-4934, 2016.

[22] M. Mirhosseini, J. Pou, and V. G. Agelidis, "Individual phase current control with the capability to avoid overvoltage in grid-connected photovoltaic power plants under unbalanced voltage sags," IEEE Trans. Power Electron., vol. 30, no. 10, pp. 5346-5351, Oct. 2015.

[23] X. Guo, Z. Lu, B. Wang, X. Sun, L. Wang, and J. M Guerrero, "Dynamic Phasors-Based Modeling and Stability Analysis of Droop-Controlled Inverters for Microgrid Applications," IEEE Trans. Smart Grid, vol. 5, no. 6, pp. 2980-2987, Nov. 2014.

[24] Das, S. N. Ananthan and S. Santoso, "Estimating zero-sequence impedance of three-terminal transmission line and Thevenin impedance using relay measurement data," Protection and Control of Modern Power Systems, vol. 3, pp. 1-10, December 2018
[25] F. Tossani, F. Napolitano, F. Rachidi and C. A. Nucci, "An Improved Approach for the Calculation of the Transient Ground Resistance Matrix of Multiconductor Lines," IEEE Trans. Power Del., vol. 31, no. 3, pp. 1142-1149, June 2016.

[26] M. Dewadasa, A. Ghosh, G. Ledwich, "Dynamic Response of Distributed Generators in a Hybrid Microgrid," IEEE Power and Energy Society General Meeting, 2011, pp. 1-8.

[27] R. Majumder, F. Shahnia, A. Ghosh, G. Ledwich, M. Wishart, F. Zare, "Operation and Control of a Microgrid Containing Inertial and Non-Inertial Micro Sources," IEEE Region 10 Conference, 2009, pp. 1-6.

[28] F. Mulolani, M. Armstrong, "Space Vector Modulation Direct power control of Grid-Connected Photovoltaic Converter with Reactive Power Compensation," IET International Conference on PEMD, pp. 1-6, 2014.

[29] F. Wang, J.L. Duarte, M.A.M. Hendrix, "Pliant Active and Reactive Power Control for Grid-Interactive Converters Under Unbalanced Voltage Dips," IEEE Transactions on Power. Electron., vol. 26, no. 5, pp. 1511-1521, May 2011.

[30] A. Camacho, M. Castilla, J. Miret, et al, "Control Strategy for Distribution Generation Inverters to Maximize the Voltage Support in the Lowest Phase During Voltage Sags," IEEE Trans. Ind. Electron., vol. 65, no. 3, pp. 2346-2355, March 2018.

[31] X. Chen, Y. Hou, S.Y. Hui, "Distributed Control of Multiple Electric Springs for Voltage Control in Microgrid," IEEE Trans. Smart Grid, vol. 8, no. 3, pp. 1350-1359, May. 2017.

[32] S. Ayasun and A. Gelen, "Stability analysis of a generator excitation control system with time delays," Electr. Eng., vol. 91, pp. 347-355, Dec. 2010.

[33] S.E. Mohamed, J. Geza and A. Chad, "A Secondary Voltage Control Strategy for Transmission Level Interconnection of Wind Generation," IEEE Trans. Power Electron., vol. 23, no. 3, pp. 1178-1190, May 2008.

[34] W. Xiao, K. Torchyan, M.S.E. Moursi, L.K. James and J.Life, "Online Supervisory Voltage Control for Grid Interface of Utility-Level PV Plants," IEEE Trans. Sustainable Energy, vol. 5, no. 3, pp. 843-853, July 2014.

[35] C. Huang, F. Li, T. Ding, Y. Jiang, J. Guo and Y. Liu, "A Bounded Model of the Communication Delay for System Integrity Protection Schemes," IEEE Trans. Power Del., vol. 31, no. 4, pp. 1921-1933, Aug. 2016.

[36] S.E. Mohamed, B.J. Birgitte and A.R. Mansour, "Novel STATCOM Controller for Mitigating SSR and Damping Power System Oscillations in a Series Compensated Wind Park," IEEE Trans. Power Electron., vol. 25, no. 2, pp. 429-441, Feb. 2010.

[37] F. A. Viawan, D. Karlsson, A. Sannino, J. Daalder, "Protection Scheme for Meshed Distribution Systems with High Penetration of Distributed Generation,” Power Systems Conference, pp. 99-104, March 2006.

\section{BIOGRAPHIES}

Xubin Liu (S'14) received the B.E. degree in automation from the College of Electrical Engineering in Northwest University for Nationalities, Lanzhou, China in 2013, and the Ph.D. degree in electrical engineering from Hunan

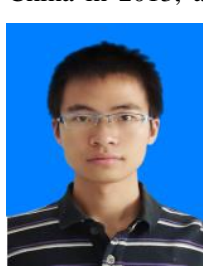
University, Changsha, China in 2019

$\mathrm{He}$ is currently a Postdoctoral Researcher with the School of Electrical and Electronic Engineering, Huazhong University of Science and Technology, Wuhan 430074, China. His research interests include power system dispatch, self-healing of smart grid, and power electronics control.

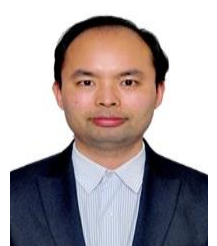
technologies.
Canbing Li (M'06-SM'13) received the B.E. and Ph.D degree from Tsinghua University, Beijing, China, in 2001 and 2006, respectively, both in electrical engineering.

$\mathrm{He}$ is currently a Professor with Shanghai Jiaotong University, Shanghai, China. His research interests include power systems, smart grid, renewable energy, with an emphasis on large-scale power system dispatch, economic and secure operation of power systems, energy efficiency and energy saving in smart grid, electric demand management of data centers, vehicle-to-grid 


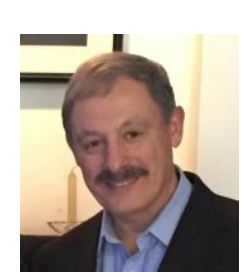

Mohammad Shahidehpour (F'01) received the Honorary Doctorate degree from the Polytechnic University of Bucharest, Bucharest, Romania. He is a University Distinguished Professor, Bodine Chair Professor, and Director of the Robert W. Galvin Center for Electricity Innovation at Illinois Institute of Technology. Dr. Shahidehpour is a Fellow of the American Association for the Advancement of Science (AAAS) and the National Academy of Inventors (NAI). He is also a member of the US National Academy of Engineering.

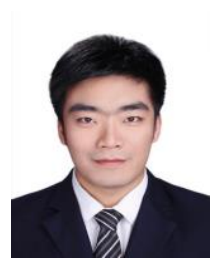

Xinyu Chen (M'14) received the B.S. and Ph.D. degrees in electrical engineering from Tsinghua University, Beijing, China, in 2009 and 2014, respectively. He was an exchange Ph.D. student at Harvard University, Cambridge, MA, USA, in 2012.

From 2015 to 2016, he was a Postdoctoral Researcher with Harvard University. Since 2016, he has been a Lecturer with Harvard University. He is currently a Professor with the School of Electrical and Electronic Engineering, Huazhong University of Science and Technology, Wuhan 430074, China. His research interests include power system operation and planning, multienergy system optimization, renewable energy integration, and energy policy.

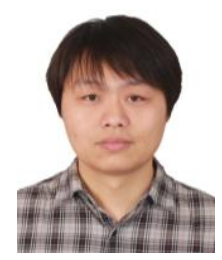

Jun Yi received the B.Sc. and M.Sc. degrees from Wuhan University, Wuhan, China, in 2001 and 2004, respectively, the Ph.D. degree from Electric Power Research Institute (EPRI), Beijing, China, in 2007, all in electrical engineering. He is currently a professor level senior engineer with EPRI, Beijing, China. His research interests include power systems, smart grid, renewable energy, et al.

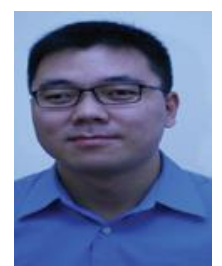

Qiuwei Wu (M'08, SM'15) obtained the PhD degree in Power System Engineering from Nanyang Technological University, Singapore, in 2009. He was a senior R\&D engineer with Vestas Technology R\&D Singapore Pte Ltd from Mar. 2008 to Oct. 2009. He has been working at Department of Electrical Engineering, Technical University of Denmark (DTU) since Nov. 2009 (PostDoc Nov. 2009-Oct. 2010, Assistant Professor Nov. 2010-Aug. 2013, Associate Professor since Sept. 2013). He was a visiting scholar at the Department of Industrial Engineering \& Operations Research (IEOR), University of California, Berkeley, from Feb. 2012 to May 2012 funded by the Danish Agency for Science, Technology and Innovation (DASTI), Denmark. He was a visiting professor named by Y. Xue, an Academician of the Chinese Academy of Engineering, at Shandong University, China, from Nov. 2015 to Oct. 2017. He was a visiting scholar at the School of Engineering and Applied Sciences, Harvard University from Nov. 2017-Oct. 2018 funded by the Otto Mønsted Fond.

His research interests are operation and control of power systems with high penetration of renewables, including wind power modelling and control, active distribution networks, and operation of integrated energy systems. He is an Editor of IEEE Transactions on Smart Grid and IEEE Power Engineering Letters. He is also an Associate Editor of International Journal of Electrical Power and Energy Systems, and Journal of Modern Power Systems and Clean Energy. He is a subject editor for IET Generation, Transmission \& Distribution, and a subject editor and regional editor for Europe for IET Renewable Power Generation.

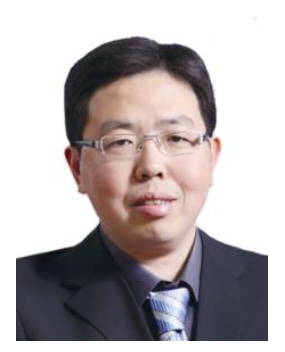

Kai Sun (M'12-SM'16) received the B.E., M.E., and $\mathrm{Ph} . \mathrm{D}$. degrees in electrical engineering from Tsinghua University, Beijing, China, in 2000, 2002, and 2006, respectively.

He joined the faculty of Electrical Engineering, Tsinghua University, in 2006, where he is currently an Associate Professor. From Sep 2009 to Aug 2010, he was a Visiting Scholar at Department of Energy Technology, Aalborg University, Aalborg, Denmark. From Jan to Aug 2017, he was a Visiting Professor at Department of Electrical and Computer Engineering, University of Alberta, Edmonton, Canada. His current research interests include power electronics for renewable generation systems, microgrids, and energy internet.

Dr. Sun is a member of IEEE Power Electronics Society Sustainable Energy Systems Technical Committee, a member of IEEE Power Electronics Society Power and Control Core Technologies Committee, and a member of IEEE Industrial Electronics Society Renewable Energy Systems Technical Committee. Dr. Sun serves as an Associate Editor for IEEE Transactions on Power Electronics, IEEE Journal of Emerging and Selected Topics in Power
Electronics, and Journal of Power Electronics. Dr. Sun served as the TPC Vice Chair of IEEE ECCE2017 and IEEE ECCE-Asia2017. He was a recipient of Delta Young Scholar Award in 2013, and Youth Award of China Power Supply Society (CPSS) in 2017.

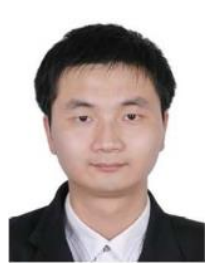

Bin Zhou (S'11-M'13) was born in Hunan Province, China, in 1984. He received the B.E. degree in electrical engineering from Zhengzhou University, Zhengzhou, China, in 2006, the M.E. degree in electrical engineering from South China University of Technology, Guangzhou, China, in 2009, and the Ph.D. degree from Hong Kong Polytechnic University, Hong Kong, in 2013. Now, he is an Associate Professor in the College of Electrical and Information Engineering, Hunan University, Changsha, China. His main fields of research include smart grid operation and planning, renewable energy generation, and energy efficiency. 